OPEN ACCESS

Edited by:

Marcelo J Dapino,

The Ohio State University,

United States

Reviewed by:

Venu Gopal Madhav Annamdas,

Continental, Germany

Tianhong Yan,

China Jiliang University, China

*Correspondence:

Chunlong Fei

clfei@xidian.edu.cn

Specialty section:

This article was submitted to

Smart Materials,

a section of the journal

Frontiers in Materials

Received: 30 June 2021 Accepted: 26 October 2021

Published: 18 January 2022

Citation:

Chen J, Fei C, Lin D, Gao P, Zhang J, Quan Y, Chen D, Li D and Yang Y (2022) A Review of UltraHigh Frequency Ultrasonic Transducers.

Front. Mater. 8:733358.

doi: 10.3389/fmats.2021.733358

\section{A Review of UltraHigh Frequency Ultrasonic Transducers}

\author{
Jun Chen ${ }^{1}$, Chunlong Fei ${ }^{1 *}$, Danmei Lin ${ }^{1}$, Pengkai Gao ${ }^{1}$, Junshan Zhang ${ }^{2}$, Yi Quan ${ }^{3}$, \\ Dongdong Chen ${ }^{1}, \mathrm{Di} \mathrm{Li}^{1}$ and YinTang Yang ${ }^{1}$
}

${ }^{1}$ School of Microelectronics, Xidian University, Xian, China, ${ }^{2}$ School of Equipment Management and Support, University of People's Armed Police, Xi'an, China, ${ }^{3}$ School of Xi'an Jiaotong University, Xian, China

The ultrahigh-frequency (UHF) ultrasonic transducers are active in various fields, including nondestructive evaluation in the semiconductor industry, microscopic biological organization imaging in biomedicine, particle manipulation, and so on. In these fields ultrahigh-frequency (UHF) ultrasonic transducers play a critical role in the performance of related equipment. This article will focus on the topic of ultrahigh-frequency ultrasonic transducers' preparation, and reviews three aspects: material selection, focus design, and acoustic energy transmission matching. Provides a summary of the current research status, and puts forward some views on the future development of UHF ultrasound devices.

Keywords: ultrahigh frequency, ultrasonic transducer, piezoelectric material, MEMS technology, acoustic lens, scanning acoustic microscope

\section{INTRODUCTION}

As an energy conversion device, the ultrasonic transducer can convert electrical energy into sound energy. Ultrasonic transducers excited by different working frequencies can emit ultrasonic waves of different frequencies. KHz-level ultrasound is generally used for large-scale and long-distance detection, like underwater sonar. In $1-10 \mathrm{MHz}$, the ultrasonic transducer of this frequency band is usually used in the field of large-size parts non-destructive testing. Up to $100 \mathrm{MHz}$, medical highfrequency ultrasound is roughly distributed in this frequency range. When it is greater than $100 \mathrm{MHz}$, it is usually collectively referred to as UHF. The UHF ultrasonic transducer can emit ultra-small wavelength ultrasonic waves because of its extremely high center frequency, which makes it a core component in the high-resolution imaging equipment- Scanning Acoustic Microscope (SAM) (Supplementary Figure S1). SAM (Makra et al., 2020)is widely used in non-destructive testing, biological microstructure imaging (Fei et al., 2016; Zhang et al., 2017), and biological cell research (Weiss et al., 2007). Moreover, acoustic tweezers (Supplementary Figure S1) based on ultra-high frequency ultrasound transducers (Chen et al., 2017; Lim and Shung, 2017) can be used for the manipulation of very small particles, and have great application value in single-cell research and micro-assembly. Therefore, the preparation of UHF ultrasonic transducers is extremely important.

This article will introduce three important aspects in the preparation process of high-frequency ultrasonic transducers. Introduction section introduces different materials for UHF transducer and analysis their advantages and disadvantages. Material Selection of Ultrasound Generation section present various transducer focus method and emphasize the difference between the low-frequency lens and high-frequency lens. Focusing Design of Ultrasonic Emission Energy section describes the acoustic energy transmission matching problem and mentions a new type of metal-polymer structure matching layer for the UHF ultrasonic transducer. 


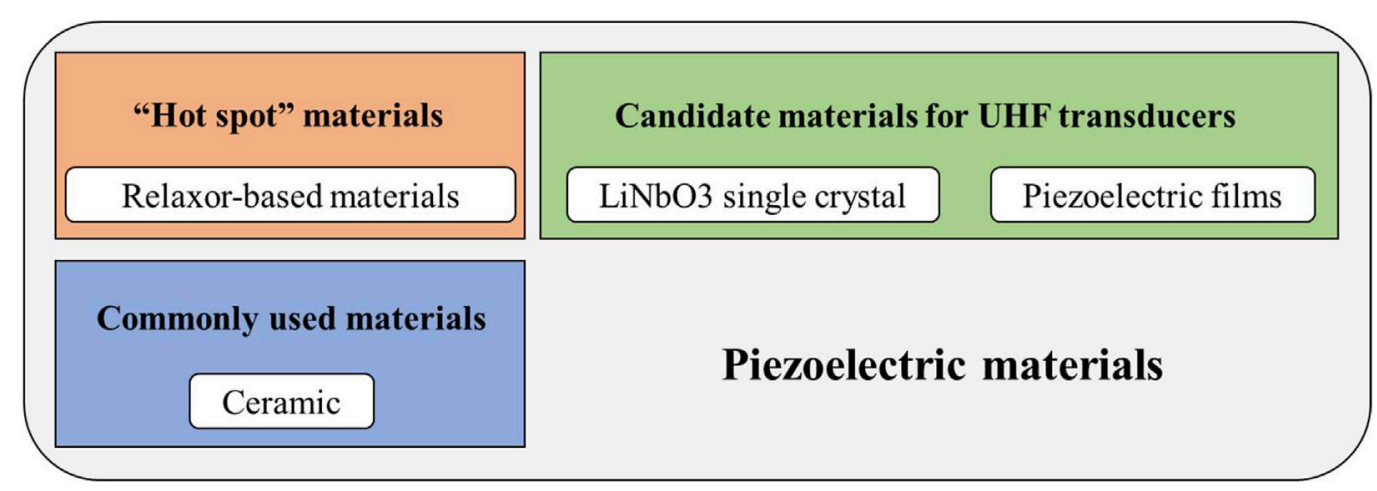

FIGURE 1 | Block diagram of Material selection.

\section{MATERIAL SELECTION OF ULTRASOUND GENERATION}

\section{Description of This Section}

There are many types of piezoelectric materials. It is necessary to have a general understanding of the existing materials for choosing piezoelectric materials suitable for preparing ultrahigh frequency ultrasonic transducers. As shown in Figure 1, this section mainly introduces four types of well-known piezoelectric materials. The first type is piezoelectric ceramics, which have long development history and widespread application in various fields for low-cost, good piezoelectric properties. The second class is relaxor-based materials. Whether ceramic or single crystal is the hot research direction of many materials scholars for the advantages of excellent piezoelectric constant and electromechanical coupling coefficient. The third is singlecrystal materials, among which LiNbO3 have been many successful cases in the preparation of ultra-high frequency ultrasonic transducers. So it is an optional material; the fourth is piezoelectric film. With the development of MEMS technology, its preparation process has become more and more mature. The convenience of piezoelectric materials' thickness control makes it act a key development direction in UHF transducers' preparation in the future. The follow-up of this section will describe the four materials in terms of their applicability in ultra-high frequency ultrasonic transducer devices' preparation.

\section{Ceramic}

Ceramic is a polycrystalline structure composed of many crystal grains of different sizes, and the crystal grains of the same orientation form crystal domains together. Due to the random orientation of the ceramic's crystal domains, from a macroscopic point of view, the ceramic is isotropic, so it was initially considered to have no piezoelectricity, but we can rearrange the crystal domains through polarization to make ceramics piezoelectric. This discovery also led to the rapid development of ceramics in the application of piezoelectric ultrasonic transducers. In 1991, a miniature PZT ceramic high-frequency ultrasonic transducer $(20-80 \mathrm{MHz})$ was reported (Foster et al.,
1991) with a center frequency of $45 \mathrm{MHz}$ and a thickness of $48 \mathrm{um}$. The grain size of ceramics (Supplementary Figure S2) is usually unevenly distributed in a few microns or tens of microns (Randall et al., 1998; Haertling, 1999; Kong et al., 2000; Pérez et al., 2005; Kamel and de With, 2008; Sangsubun et al., 2008), this is very close to the thickness of piezoelectric materials. In the process of lapping the ceramic material to the specified thickness, as the material thickness gradually approaches the grain size, its mechanical strength will be significantly reduced, and the material will become fragile. The material may fall off in the form of grains resulting in poor material uniformity. The piezoelectric performance of the target material obtained in this way will greatly reduce, and it may even become unpredictable. This is a fatal weakness that prevents them from being used in UHF devices' production.

\section{Relaxor-Based Materials}

Ceramics based on PZT solid solutions have low production costs and good piezoelectric properties. They have been occupying the choice of ultrasonic transducers for many years. Until the emergence of relaxor-based materials, this situation has been broken. Since then, it has been a hot research direction because of their extremely high piezoelectric constant d33 (Park and Shrout, 1997b) and electromechanical coupling coefficient kt (Park and Shrout, 1997a). The performance parameters of several materials are shown in Table $\mathbf{1}$ (Chen et al., 2014). Due to the similarities in the properties of different materials in this category, only a few representative materials are listed here.

It can be seen from the table that most relaxor-based materials have $\mathrm{d} 33$ as high as 2000 or even greater, and the max kt is higher

TABLE 1 | Performance parameters of relaxor-based materials-thickness vibration mode.

\begin{tabular}{lcccc}
\hline & Cut & $\boldsymbol{d}_{\mathbf{3 3}}(\boldsymbol{p} \boldsymbol{C} / \boldsymbol{N})$ & $\boldsymbol{k}_{\boldsymbol{t}}$ & $\boldsymbol{\varepsilon}_{\mathbf{3 3}}$ \\
\hline PZN & 001 & 1,100 & 0.49 & 3,600 \\
PZN-0.08 PT & 001 & 2070 & 0.48 & 4,200 \\
PMN-0.28 PT & 001 & 2,365 & 0.63 & 1,032 \\
PIN-0.40PMN-0.33 PT & 001 & 2,742 & 0.59 & 659
\end{tabular}


than 0.60. Piezoelectric performance is excellent, but the speed of sound of this type of material is usually not high, which will cause the thickness of the material to be thinner under the same center frequency requirement. This will greatly increase the difficulty of processing, and even cannot be manufactured. In addition, the high dielectric constant of the relaxor ferroelectric will make the area of the piezoelectric unit that meets the 50 -ohm impedance matching too small, which will greatly increase the difficulty of machining and will also affect the ultrasonic emission intensity. Therefore, although the relaxor ferroelectric has excellent piezoelectric properties, it is not a suitable choice for the preparation of ultra-high frequency ultrasonic transducers due to the limitation of other factors.

\section{LiNbO3 Single Crystal}

Since it was invented by Jan Czochralski in 1916 (Uecker, 2014), the growth of bulk single crystals technique (Czochralski Method) has been widely spread and developed, and then the Bridgman method (Chen et al., 2003) using crucibles to prepare single crystals was reported. This method can effectively ensure that the raw material composition ratio is affected by the external environment. Subsequently, based on these two methods, many new preparation methods have been introduced through process improvement. The continuous maturity of single crystal preparation technology has also promoted the research and development of single crystals.

Single crystal has a very high piezoelectric constant $\mathrm{d} 33$ and electromechanical coupling coefficient kt, making it a promising candidate for making high-performance transducers. Moreover, unlike polycrystalline ferroelectric ceramics, single crystals are not limited by factors such as crystal grains and porosity and have the potential to produce ultra-high frequency transducers. The grown large-size single-crystal generally needs to be cut into the plate, single crystal has a crystallographic axis, and the cutting direction affects the piezoelectric performance of the single crystal. Different device performance requirements corresponding to different cutting types. A plate cut with its surface perpendicular to the $x$-axis of a crystal is called $\mathrm{x}$-cut, and the same as other axes.

LiNbO3 single crystal with relatively high acoustic velocity, excellent piezoelectric properties, and small dielectric constant, have advantages in manufacture high frequency and large aperture ultrasonic transducers. For better piezoelectric property, we usually choose $36^{\circ}$ Y-cut $\mathrm{LiNbO} 3$ as the transducer's piezo layer. The detail parameters include thickness mode electromechanical coupling, dielectric permittivity, longitudinal wave velocity is about $0.49,39$, $7,340 \mathrm{~m} / \mathrm{s}$, respectively. To make UHF transducers based on LiNbO3, we need to lap it to a few microns, which can be achieved in theory, but the process is quite difficult. To meet the requirements of high-resolution imaging of biological microstructures, Chunlong Fei (Fei et al., 2016) prepared a $100-300 \mathrm{MHz}$ UHF ultrasound transducer. As shown in Supplementary Figure S3, you can see on the left that the thickness of the piezoelectric layer of the $300 \mathrm{MHz}$ LN UHF ultrasound transducer is only $9 \mathrm{um}$, the UBM ultrasound scan image of zebrafish eye on the right, the internal structure of the eye can be distinguished.

As shown in Figure 2, Hae Gyun Lim and K. Kirk Shung (Lim and Shung, 2017) prepared an LN piezoelectric layer with a thickness of $7.1 \mathrm{um}$ and used a focus design to generate a UHF probe capable of emitting a $6.5 \mathrm{um}$ width beam. The UHF transducer has a center frequency of up to $400 \mathrm{MHz}$, which achieves Acoustic tweezers capture a single red blood cell ( 7.5 um). Xiaoyang Chen (Chen et al., 2017) used a 6um thick LN to prepare an ultra-high frequency ultrasonic transducer with a resonant frequency of $526 \mathrm{MHz}$, and achieved selective acoustic tweezers for particles in the range of 3-10 um by changing the excitation, as shown in Figure 2.

Although there have been reports of the above-mentioned UHF LN single-crystal devices, it is still extremely difficult to control the thickness of LN materials of a few microns. The preparation process requires a lot of time and effort, and with the further increase of the center frequency, the degree of difficulty may be more than a simple linear increase, so to increase the upper limit of UHF ultrasonic transducers, new materials are needed to provide the feasibility of extremely low thickness control.

\section{Piezoelectric Films}

With the development of MEMS technology, piezoelectric film manufacturing technology has also made great progress, which provides a new choice for piezoelectric materials for ultra-high frequency ultrasonic transducers. Films based on traditional ferroelectric materials have excellent piezoelectric properties and mature thickness control technology. So far, many researchers have done a lot of work in this area. As early as 1997, DA Barrow produced a 60um thick PZT film through the sol-gel method (Barrow et al., 1997). This method firstly disperses PZT particles into a PZT sol-gel matrix to achieve a 0-3 ceramic/ ceramic composite. Then the ceramic/ceramic composite is spincoated and distributed on the silicon substrate, followed by sintering and annealing, repeat the above steps layer by layer until the specified thickness is reached. As shown in Supplementary Figure S4, it is a 20 um PZT film coated with ten layers. The PZT films prepared by this method have a good piezoelectric constant $\mathrm{d} 33=325 \mathrm{pC} / \mathrm{N}$.

Subsequently, many UHF transducer devices based on PZT films were published. In 2006, P Marechal improved the sol-gel and introduced a vacuum precursor solution filling method to improve the quality of the film. A 13 um thick PZT film was fabricated on the Pt-substrate, with this film, a $103 \mathrm{MHz}$ ultrahigh frequency ultrasonic device was fabricated (Marechal et al., 2006). The pulse-echo test results are shown in the upper part of Supplementary Figure S5. The $-6 \mathrm{~dB}$ bandwidth reaches $70 \%$, and the pulse-echo waveform is also relatively beautiful. Then in 2008, BP Zhu grew PZT films by a ceramic powder/sol-gel solution modified composite method, and prepared a $156 \mathrm{MHz}$ PZT films transducer (Zhu et al., 2008) with a $-6 \mathrm{~dB}$ bandwidth of $50 \%$, as shown in Supplementary Figure S5, the bottom left is the experimental measurement results and the bottom right is the simulation result of PiezoCAD. 

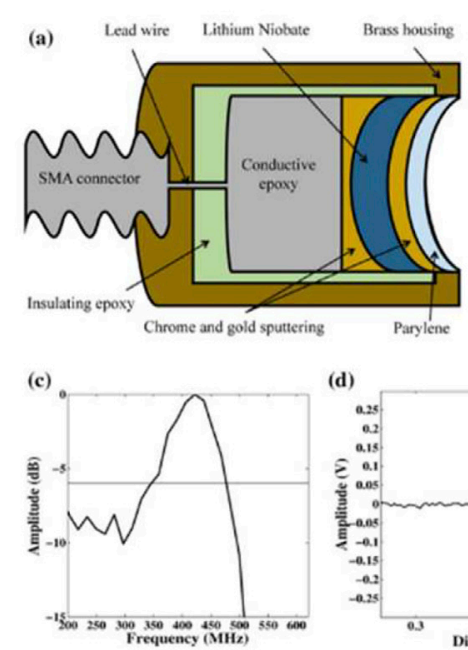

(d)
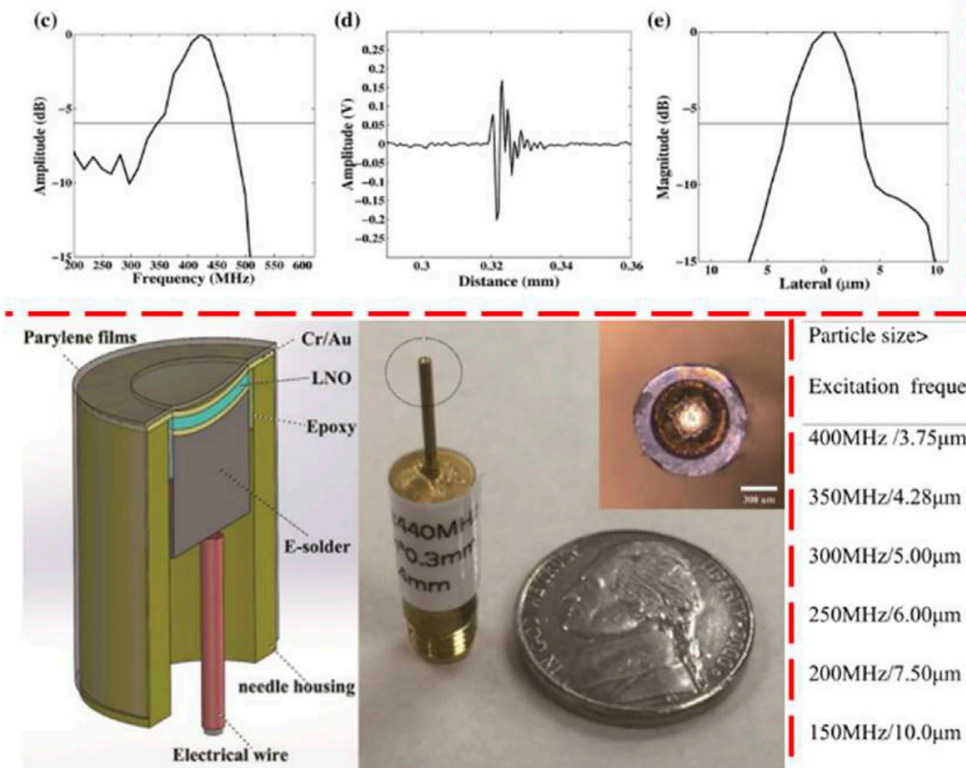

(e)

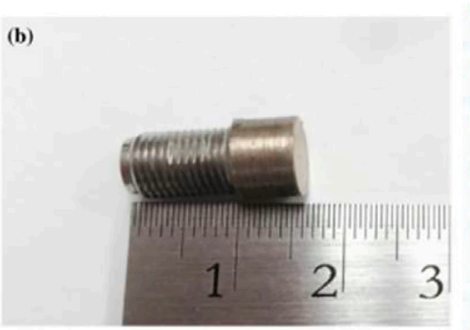

|

(c)

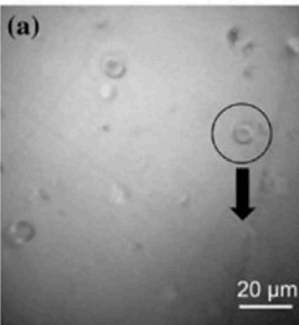

)

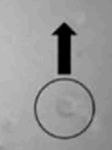

(b)

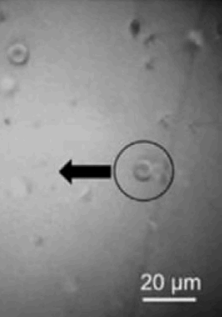

(d)

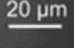

$\underline{20 \mu m}$
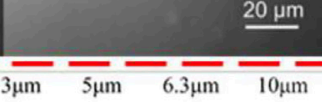

$\begin{array}{llll}\checkmark(1) & \times & \times & \times \\ \checkmark(1) & \times & \times & \times \\ \checkmark(\geq 2) & \checkmark(1) & \times & \times \\ \checkmark(\geq 2) & \checkmark(1) & \checkmark(1) & \times \\ \checkmark(\geq 2) & \checkmark(\geq 2) & \checkmark(\geq 2) & \times \\ \checkmark(\geq 2) & \checkmark(\geq 2) & \checkmark(\geq 2) & \checkmark(1)\end{array}$

FIGURE 2 | $400 \mathrm{MHz}$ ultra-high frequency ultrasonic transducer structure and performance (top left); $500 \mathrm{MHz}$ ultra-high frequency ultrasonic transducer structure (bottom left); red blood cell acoustic tweezers capture process under microscope (top right); acoustic tweezers capture particles under different excitation results (bottom right).

PiezoCAD is a simulation software derived from the KLM model. When the frequency is not particularly high, the simulation results are still relatively close, but when the frequency continues to increase, many factors that are difficult to consider are introduced by high frequency. The aspects involved in the KLM model may not be enough to ensure the accuracy of the simulation. It seems that the deviation is not particularly large here. The simulation results can still play a certain reference role. In the UHF frequency, the results of simulation through finite element calculation, such as PZFlex, COMSOL, and other software, are relatively more reliable, but as the frequency increases, the simulation time will also increase significantly. XY Chen combined composite ceramic sol-gel film technique with sol-infiltration technique and fabricated up to $300 \mathrm{MHz}$ 0-3 composite PZT films transducer (Chen et al., 2016), the center frequency of $300-\mathrm{MHz}$ is the highest value in a $\mathrm{PbTiO} 3$ based ceramic ultrasonic transducers ever reported (Supplementary Figure S6).

In consideration of environmental protection, lead-free material films have also been added to the research on the preparation of UHF transducers. ST Lau has done a series of
UHF transducer preparations based on lead-free piezoelectric films, the result shown in Supplementary Figure S7 (Lau S.-t. et al., 2010; Lau S. T. et al., 2010; Lau et al., 2011). K H Lam studied KNN/BNT ultra-high frequency ultrasonic transducer devices in the frequency range of $170-320 \mathrm{MHz}$. Pulse echo is shown in Supplementary Figure S8 (Lam et al., 2013b).

The traditional bulk piezoelectric relaxor ferroelectric material has attracted the attention of many researchers due to its extremely high piezoelectric constant and dielectric constant. It has also been seen in the application of film materials. PMN-PT film is considered to can replace the PZT film, but its extremely high dielectric constant will make it difficult to control the ultrasonic transducer device during electrical impedance matching. A feasible solution is to use a composite sol-gel method to composite PMN- PT and PZT according to a certain mixing ratio, then made them into xPMN-PT-(1-x)PZT film (Hsu et al., 2012). While retaining high piezoelectric performance, the dielectric constant is adjusted to a controllable range, such as Supplementary Figure S9, on the left is the change in dielectric constant, and on the right is the pulse-echo waveform of an ultra-high frequency transducer made 

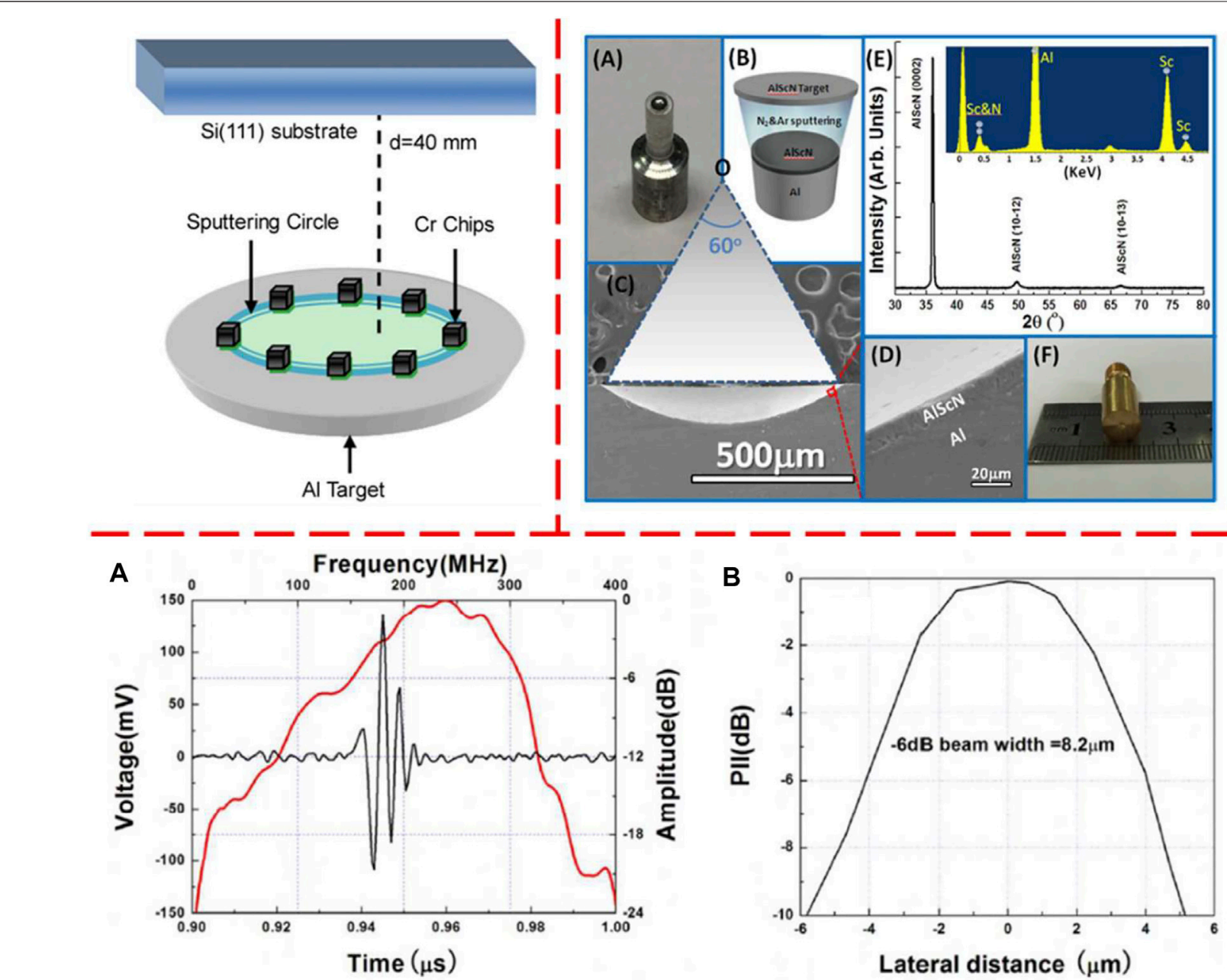

FIGURE 3 | Schematic drawing of the Cr doping sputtering system (top left); preparation of Cr-doped AIN UHF Ultrasonic Transducer (top right); Time-domain pulse/echo response (black line) and frequency spectrum (red line) and resolution of Cr-doped AIN UHF UItrasonic Transducer (bottom).

of 0.9PMN-PT-0.1PZT composite film. In addition to material composition, it is also a commonly used material modification method to change the crystallographic properties and microstructure of materials through particle doping and to change material properties. These two methods can be combined to provide more possibilities for UHF transducer materials. HS Hsu further adjusted the performance of the xPMN-PT-(1-x)PZT composite film through Ag doping (Hsu et al., 2013) and successfully fabricated an ultra-high frequency ultrasonic transducer device. The results are shown in Supplementary Figure S10.

The overall performance of the thin film prepared by the traditional ferroelectric materials has declined, but it is still related to the electrical performance of the bulk material. Furthermore, the particle doping and material composite can be used in the thin film, which will improve the performance of the material. However, there are also shortcomings. The high temperature during the film densification and annealing process cannot be withstood by other materials in the ultrasonic transducer As a result, the growth of the piezoelectric film is not completely compatible with the manufacturing process of the transducer, and secondary processing operations are usually required for the grown film. It is very difficult to operate a film of several microns, which will greatly affect the repeatability of the preparation of the transducer, the consistency cannot be guaranteed, and the process complexity is high, which is not conducive to mass production.

The semiconductor industry is developing rapidly, and its mature MEMS technology provides a new path to produce UHF transducers. Using $\mathrm{ZnO}$ and $\mathrm{AlN}$, which are commonly used in semiconductors, to replace traditional ferroelectric materials to

TABLE 2 | Material parameters of transducer design.

Dielectric properties Piezoelectric properties

Acoustic properties

$C=\frac{\varepsilon_{33} A}{t} \quad k_{t}^{2}=\frac{e_{33}^{2}}{C_{33} \varepsilon_{33}}, d_{33} \quad Z_{P}=\rho C_{m}, f=n \frac{C_{m}}{2 t}$ 
TABLE 3 | Material analysis summary.

\begin{tabular}{|c|c|c|c|}
\hline & Advantage & Shortcoming & UHF devices applicability \\
\hline Ceramic & $\begin{array}{l}\text { Low cost, complete variety, good piezoelectric } \\
\text { performance }\end{array}$ & Grain size limitation & No, the material has limitations \\
\hline $\begin{array}{l}\text { Relaxor-based } \\
\text { materials }\end{array}$ & Excellent piezoelectric performance & $\begin{array}{l}\text { Large dielectric contant makes impedance }(50 \Omega) \\
\text { matching difficult, sound velocity is not large } \\
\text { enough }\end{array}$ & No it's difficult to fabricate \\
\hline $\begin{array}{l}\text { LiNbO3 single } \\
\text { crystal }\end{array}$ & $\begin{array}{l}\text { Good piezoelectric performance, large sound } \\
\text { velocity, no grain size limitation, small dielectric } \\
\text { constant }\end{array}$ & Difficult to realize precise thickness control & $\begin{array}{l}\text { Yes, but there is a frequency limit, and it is } \\
\text { difficult to reach more higher frequency }\end{array}$ \\
\hline Ferroelectric films & $\begin{array}{l}\text { Good piezoelectric performance, precise } \\
\text { thickness control }\end{array}$ & $\begin{array}{l}\text { Poor compatibility between material growth and } \\
\text { transducer preparation }\end{array}$ & $\begin{array}{l}\text { Yes, but manufacturing repeatability needs } \\
\text { to be improved }\end{array}$ \\
\hline $\begin{array}{l}\text { Semiconductor } \\
\text { films }\end{array}$ & Mature technology, precise thickness control & Poor piezoelectric performance & $\begin{array}{l}\text { Yes, but material performance needs to be } \\
\text { improved }\end{array}$ \\
\hline
\end{tabular}

prepare ultra-high frequency ultrasonic transducers, its consistency and reliability will be better in terms of process realization. But in terms of material piezoelectric properties, $\mathrm{ZnO}$ and $\mathrm{AlN}$ are far inferior to traditional ferroelectric materials. It is also necessary to improve the performance of the material by doping. For example, the piezoelectric constant of AlN piezoelectric film sputtered by Cr doping (Luo et al., 2009) will be improved to a certain extent, as shown in Figure 3. E Wistrela also mentioned that XRD and surface topography analysis (Wistrela et al., 2018) can as a straightforward approach to estimate the piezoelectric activity of $\mathrm{Cr}$ doped AlN thin films. K San reported a $40-80 \mathrm{MHz}$ Cr-doped AlN ultrasonic transducer (Sano et al., 2018). BP Zhu reported a $200 \mathrm{MHz}$ Cr-doped AlN ultra-high frequency ultrasonic transducer (Zhu et al., 2017), the preparation of the transducer is shown in the upper right of Figure 3, the pulseecho and resolution are shown in Figure 3 bottom left.

The latest research report that introduces $\mathrm{Yb}$ into aluminum nitride (AlN) leads to a large enhancement in the material's piezoelectric response $(\mathrm{d} 33)$. The maximum $\mathrm{d} 33$ is calculated to be over $100 \mathrm{pC} / \mathrm{N}$, which is 20 times higher than that of AlN(Hirata et al., 2021). However, there are no reports of successful preparation of devices from related materials.

\section{Summary of This Section}

The selection of piezoelectric materials is the most critical step in the preparation of ultrasonic transducer devices. The choice of materials needs to be considered from two major aspects. One aspect is the process, which determines whether the material can successfully fabricate UHF devices. The thickness of the piezoelectric material is usually half a wavelength at the working frequency. When the working frequency is up to the ultra-high frequency, the thickness control of the piezoelectric material of a few microns is a big problem. Therefore, when selecting the material, it is necessary to consider its growth process, processing difficulty, and whether it can be better compatible with the preparation process of the transducer device to ensure the stability of the preparation process of the transducer. Another aspect is the performance of the material, which determines the final device performance. The parameters

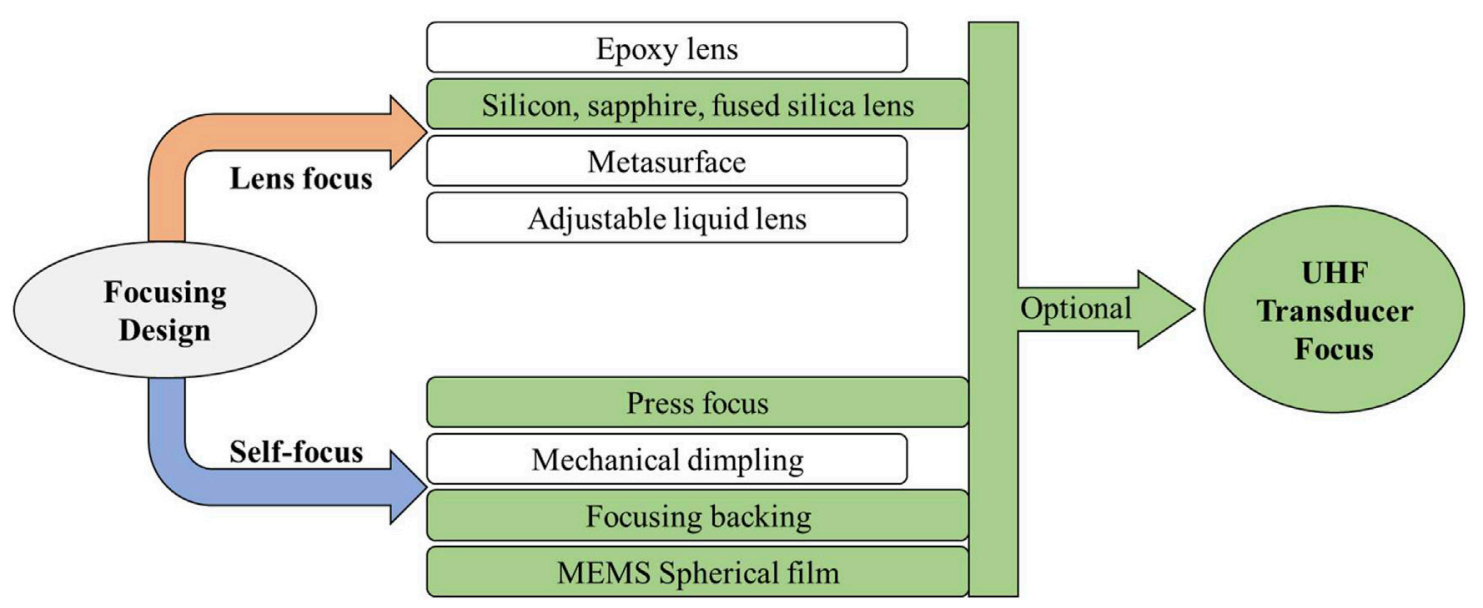

FIGURE 4 | Block diagram of Focusing Method. 

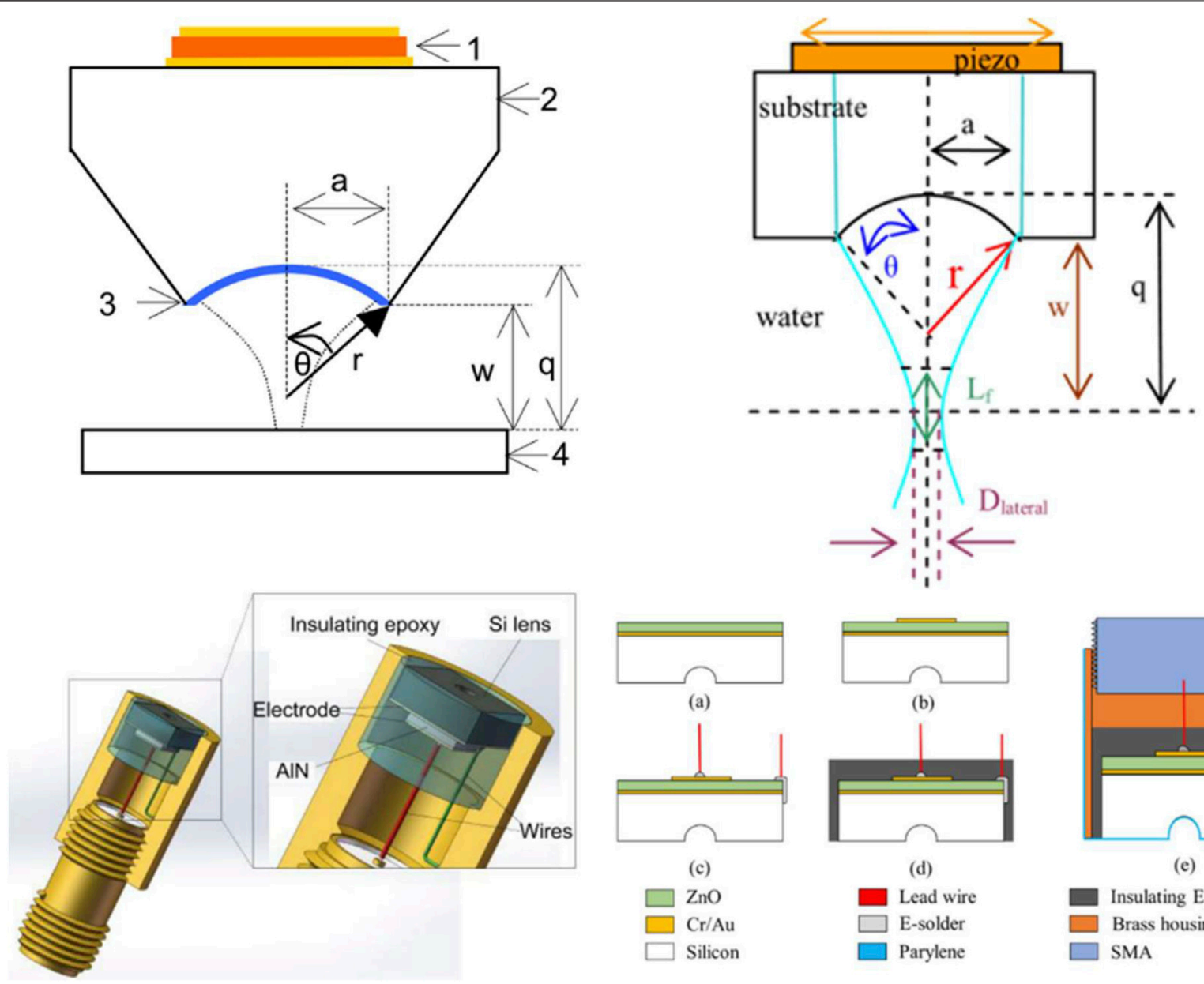

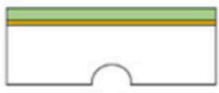

(a)

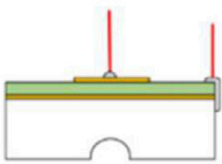

(c)

$\mathrm{ZnO}$

$\mathrm{Cr} / \mathrm{Au}$

Silicon

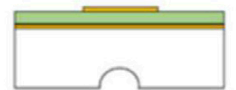

(b)

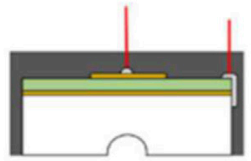

(d)

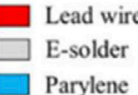

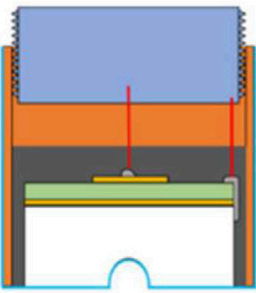

(e)

Insulating Epoxy

Brass housing

SMA

FIGURE 5 | Schematic diagram of UHF ultrasonic transducer with silicon acoustic lens.

in the thickness vibration mode are mainly considered here. Generally, the material parameters considered in the preparation of ultrasonic transducers are piezoelectric constant $d_{33}$, electromechanical coupling coefficient $k_{t}$, dielectric constant $\varepsilon_{33}$, acoustic impedance $Z_{p}$, and sound velocity $c_{m}$. Compared with conventional devices, UHF devices pay more attention to the speed of sound and dielectric constant. The former determines the final thickness of the piezoelectric material, and the latter determines the final area size of the piezoelectric material when the electrical impedance is matched to $50 \Omega$. Reasonable thickness and area size can ensure the success of preparing UHF transducers. Then we need to consider the piezoelectric constant and electromechanical coupling coefficient, which affect the final signal amplitude and energy loss of the device. The material parameters mentioned above are all in Table 2, where $n$ is an odd integer and usually $\mathrm{n}=1$, it means the lowest resonant frequency. $C$ is the clamped capacitance, $A$ is the area of piezoelectric materials, $t$ is the thickness of piezoelectric materials, $e_{33}$ is the piezoelectric stress constant, $c_{33}$ is the elastic constant, $c_{m}$ is the speed of sound inside the piezoelectric material, $\rho$ is the density.
There is no best material, only the most suitable material. Table 3 analyzes and compares the four types of piezoelectric materials' advantages and disadvantages mentioned, and gives an evaluation of the applicability of these four materials in ultra-high frequency ultrasonic devices' preparation.

\section{Focusing Design of Ultrasonic Emission Energy Description of This Section}

The higher the frequency, the greater the attenuation of ultrasonic energy. To concentrate more emitted energy, the focus design of the transducer is usually necessary. Moreover, the UHF device has a higher frequency and smaller thickness, so its focus needs to consider tremendous sound attenuation and difficulty in process realization.

As shown in Figure 4, the focus design in this article divides into two directions. One is to achieve focusing by adding a lens to the surface of the piezoelectric material, which includes epoxy lens, metamaterial lens, adjustable liquid lens, Silicon lens, sapphire lens, and fused silica lens. The other is to achieve the 


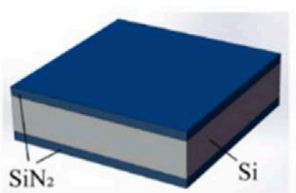

1st. Hard mask preparation using LPCVD $\mathrm{SiN}_{2}$.

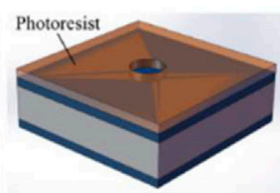

2nd. Pattern the areas to be etched using photolithography

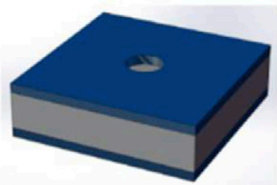

3rd. RIE etching of $\mathrm{SiN}_{2}$ and remove residual photoresist.

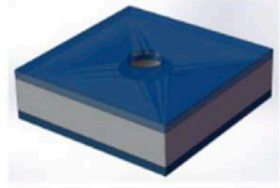

4th. HNA etching of silicon.

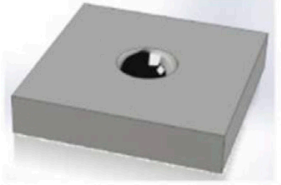

5th. Remove hard mask of $\mathrm{SiN}_{2}$

(b)

(a)

(c)
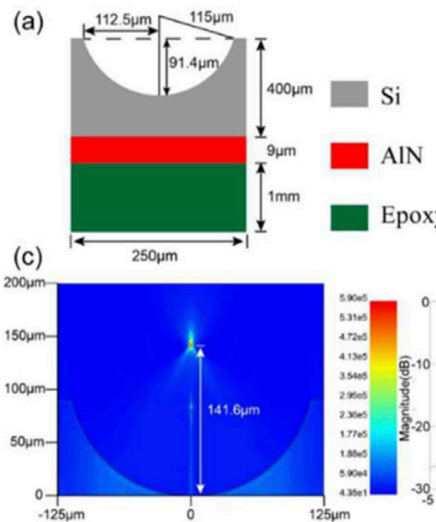

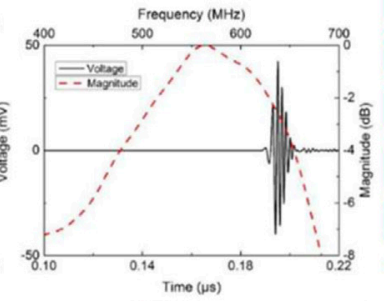

(d)

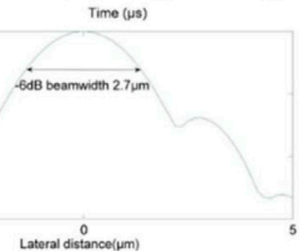

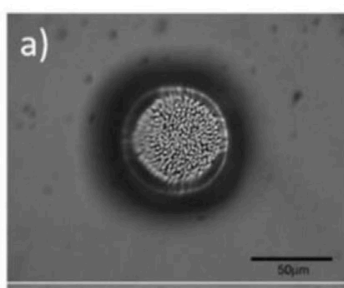

c)

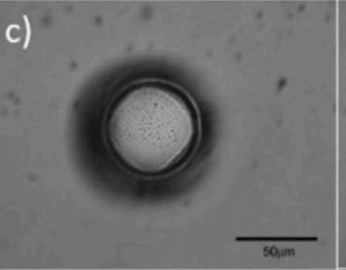

e) b)

d)
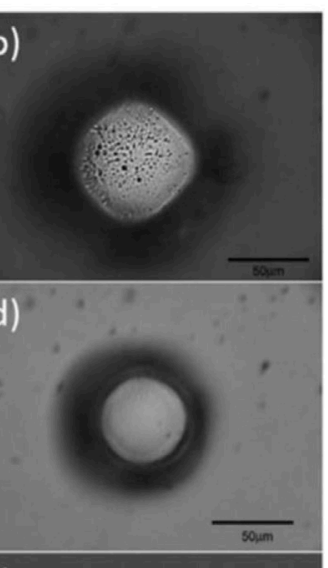

f)
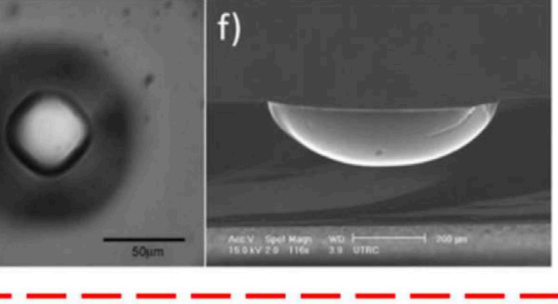

(a)
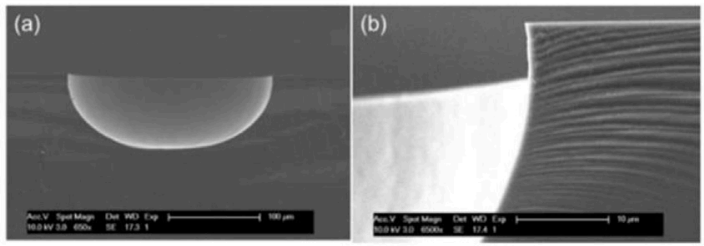

FIGURE 6 | The flow chart of chemical wet etching silicon lens and the SEM photographs of the silicon lens prepared by this method (top); silicon lens simulation and UHF device performance and the SEM photographs of dry-etched silicon lens (bottom).
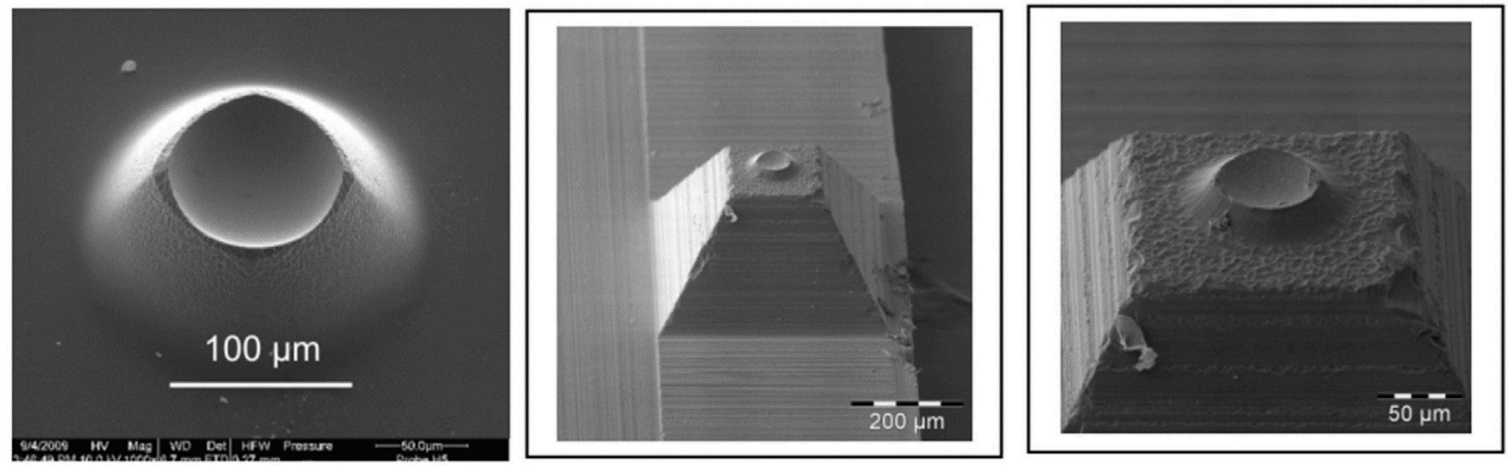

FIGURE 7 | Specially designed acoustic lens for GHz ultrasonic transducer device.

purpose of focusing by changing the shape of the piezoelectric material itself. There present four methods. The first one is to use a small ball to press the piezoelectric material to a focused shape. The second method is to lap the surface of the piezoelectric material with a mechanical grinding wheel. The third way applies a focused shape backing material. The last one combines MEMS technology to fabricate a focused shape piezoelectric material. Considering the difficulty of the process and the final focusing 

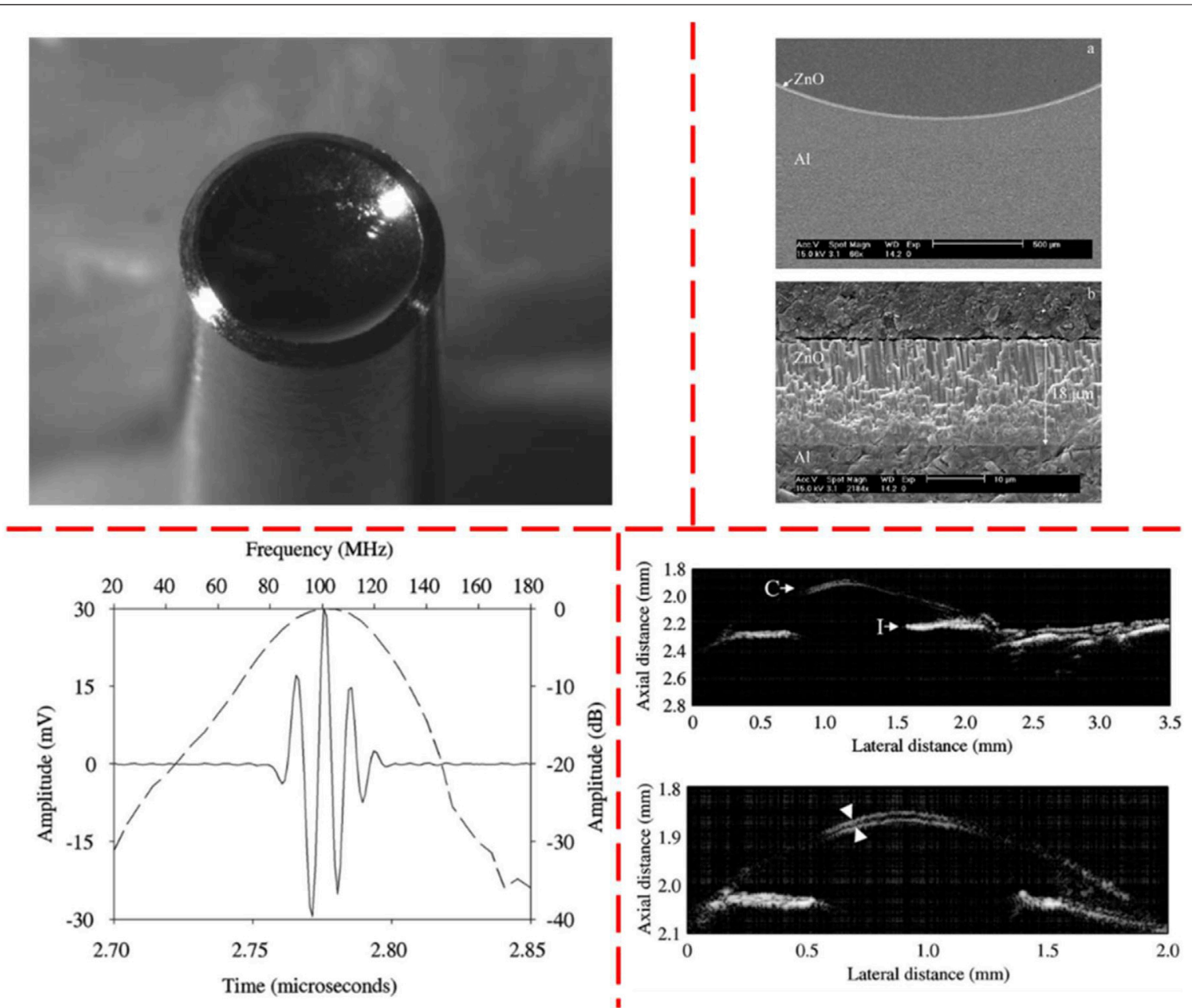

FIGURE 8 | A photograph of $100 \mathrm{MHz} \mathrm{ZnO}$ self-focus transducer (top left); The SEM cross section of $100 \mathrm{MHz} \mathrm{ZnO}$ self-focus transducer (top right); timedomain pulse/echo response (solid line) and frequency spectrum (dashed line) of $100 \mathrm{MHz} Z \mathrm{nO}$ self-focus transducer (bottom left); High resolution ultrasound image of zebrafish eye (bottom right)

effect, the focusing methods adapt to ultra-high frequency ultrasound devices' fabrication have been marked in green in the figure for easy viewing. The following content will illustrate these focusing methods.

\section{Press Focus}

Generally speaking, the most commonly used focusing method is spherical pressure focusing (Fei et al., 2018b), which uses a small ball to press a piezoelectric material to a spherical concave surface through a weight (Supplementary Figure S11). This method is simple and the cost is low, but the piezoelectric material in the UHF device is very thin. Using this method will

TABLE 4 | UHF ultrasonic transducer acoustic lens material properties.

\begin{tabular}{lccc} 
& Sapphire & Fused quartz & Si(100) \\
\hline Acoustic velocity $(\boldsymbol{m} / \mathbf{s})$ & 11,100 & 5,900 & 8,430 \\
Acoustic impedance $\left(\mathbf{1 0}^{\mathbf{6}} \mathbf{k g} / \mathbf{m}^{\mathbf{2}} \cdot \mathbf{s}\right)$ & 40 & 15.6 & 19.8 \\
Loss at $1 \mathrm{GHz}(\mathbf{d B} / \mathbf{c m})$ & $0.2-0.5$ & 12.1 & 6.5
\end{tabular}

often cause the piezoelectric material to break, and finally, make the performance of the device more difficult to predict, and the consistency is difficult Guaranteed. (Cannata et al., 2000).

\section{Mechanical Dimpling}

Another commonly used focus method is mechanical dimpling (Lam et al., 2012; Chen et al., 2013; Fei et al., 2018a). As shown in Supplementary Figure S12, the upper left is $5 \mathrm{MHz}$ mechanical focusing PMN-PT single crystal, the top right is the surface morphology of the piezoelectric material after mechanical digging, and the bottom is the production flow chart of the $35 \mathrm{MHz}$ PMN-PT IVUS mechanical focusing transducer. It can be seen in that the mechanical digging is performed on the piezoelectric material through a circular grinding wheel. The surface is made by pressing and polishing, but it is impossible to perform machining on the surface of the piezoelectric material of the ultra-high frequency device of a few microns. 

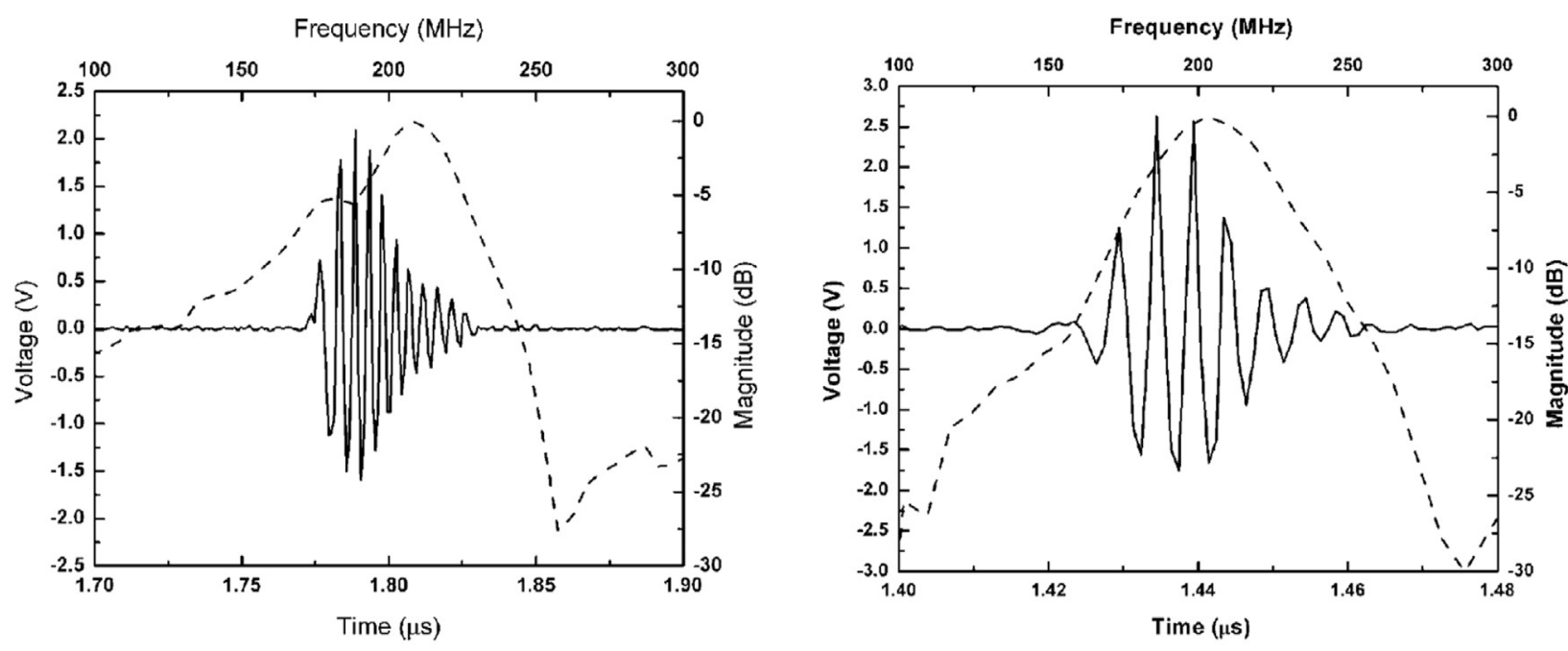

FIGURE 9|Time-domain pulse/echo response (solid line) and frequency spectrum (dashed line) of the $200 \mathrm{MHz}$ LiNbO3PF transducer (left); Time-domain pulse/ echo response (solid line) and frequency spectrum (dashed line) of the $200 \mathrm{MHz} Z \mathrm{nO}$ SF transducer (right).

\section{Acoustic Metasurface}

Acoustic metasurface (Supplementary Figure S13) is a relatively novel way of sound field control (Al Jahdali and Wu, 2016; Zhu et al., 2016), but its structure usually has a large attenuation. Furthermore, with the frequency increases, the fabrication of metasurface structure is harder to realize, which makes it very difficult to play a role in the range of UHF applications. However, it can play a great role in regulating a specific sound field.

\section{Adjustable Focus}

There is an unconventional, but very interesting lens, as shown in Supplementary Figure S14. It can flexibly change the focus point by injecting liquid to control the curvature of the lens ( $\mathrm{Li}$ et al., 2021b; Li et al., 2021c). It is hard to apply in UHF ultrasonic devices, but some special occasions may play a miraculous effect.

\section{Silicon Lens}

In the low-frequency range, epoxy can be considered to prepare a lens (Cannata et al., 2003), the epoxy lens is easy to mold and the prepared lens surface is smooth. Sapphire, fused quartz, and silicon are usually used in ultrahigh-frequency ultrasonic devices. Acoustic lenses are made by machining or etching firstly, and then $\mathrm{ZnO}$ is sputtered on the surface of the lens as piezoelectric materials to make UHF ultrasonic transducers, as shown in Figure 5 (Kushida et al., 1988; Hashimoto et al., 1991; Vispute et al., 1997; Molarius et al., 2003; Jakob et al., 2009). This production process is relatively reliable and repeatable.

In 2017, CL Fei prepared a silicon lens through chemical wet etching. The preparation process and preparation effect are shown in the upper part of Figure 6. By sputtering a $\mathrm{ZnO}$ piezoelectric layer on this lens, a $300 \mathrm{MHz}$ UHF device was successfully prepared (Fei et al., 2017). Then D Li and CL Fei reported on the silicon lens prepared by dry etching, and successfully prepared a $500 \mathrm{MHz}$ AlN ultra-high frequency ultrasonic transducer (Li et al., 2018), the performance of the silicon lens and the transducer, as shown in Figure 6 below.
Jakob mentioned in the article that the shape of the lens in Figure 7 can not only reduce the interference of the edge echo but also can concentrate more energy in the target imaging area, reducing the divergence of the beam side lobes. This kind of acoustic lens can be applied to the ultrasonic scanning microscope of the $\mathrm{GHz}$ level. However, the realization of this kind of lens is more complicated, and the cavity needs to be etched by the wet method, and then the excess part of the edge is removed by the dry method (Jakob et al., 2007; Jakob et al., 2009). Some acoustic lens materials are listed in Table 4 for reference (Hashimoto et al., 1991).

\section{Focusing Backing}

Since the acoustic lens will introduce a certain amount of attenuation, self-focusing of piezoelectric materials (Zhou et al., 2007; Jakob et al., 2009; Zhu et al., 2017) may be a better method. In this method, a focusing backing substrate is prepared in advance, and then piezoelectric material is sputtered on it, to avoid the attenuation caused by the acoustic lens. But in this way, the choice of the backing base material is more important. If the acoustic impedance of the backing material is too large from the piezoelectric material, the ultrasonic energy propagating after the phase cannot be absorbed, which will result in a larger ring in the echo signal. Al has many advantages, such as good processability, easy to process into spherical focusing grooves, good electrical conductivity, acoustic impedance closer to $\mathrm{ZnO}$ compared to other metals, higher melting point, and not being affected by the operating temperature during the preparation of piezoelectric materials. It is suitable to be a base material for self-focusing UHF transducers. JM Cannata fabricated a $100 \mathrm{MHz}$ self-focusing UHF device using $\mathrm{Al}$ as the substrate (Cannata et al., 2008) and performed high-resolution imaging of zebrafish eyes (Figure 8). $\mathrm{KH}$ Lam also chose $\mathrm{Al}$ as the substrate. A $200 \mathrm{MHz}$ self-focusing UHF device was fabricated on the substrate (Lam et al., 2013a), and the performance of the LN spherical pressure focusing UHF device was compared at the same 
TABLE 5 | Summary of focusing methods.

\begin{tabular}{|c|c|c|c|}
\hline & Advantage & Shortcoming & UHF devices applicability \\
\hline Epoxy lens & Simple molding, low cost & Large attenuation & No \\
\hline $\begin{array}{l}\text { Silicon, sapphire, fused } \\
\text { silica lens }\end{array}$ & $\begin{array}{l}\text { Low attenuation, high surface } \\
\text { smoothness }\end{array}$ & Complex process, high cost & Suitable for ultrahigh frequency, recommended method \\
\hline Metasurface & Design flexibility & Large attenuation, complex process & No \\
\hline Adjustable liquid lens & Adjustable focus & Not burst enough & No \\
\hline Process focus & Easy to operate, low cost & $\begin{array}{l}\text { Damage to piezoelectric materials, poor } \\
\text { consistency }\end{array}$ & $\begin{array}{l}\text { Applicable, but the consistency of equipment performance is } \\
\text { difficult to guarantee }\end{array}$ \\
\hline Mechanical dimpling & Easy to operate, low cost & Not suitable for microfabrication & No \\
\hline Focusing backing & Easy to operate, low cost & Relay on machining accuracy & Applicable, there is an upper limit for machining \\
\hline MEMS Spherical film & Good repeatability & Complex process, high cost & Applicable and developable direction \\
\hline
\end{tabular}

frequency. In Figure 9, it illustrates the effectiveness of the method of preparing UHF self-focusing by sputtering $\mathrm{ZnO}$ film with $\mathrm{Al}$ as the substrate, and the process stability of this method is much better than LN spherical pressure focusing.

\section{MEMS Spherical Film}

There is another way to realize transducer self-focus, which is a complete MEMS process. As shown in Supplementary Figure S15, the dome-shaped-diaphragm transducers (DSDT) (Feng et al., 2005) fabrication uses spherical balls to precisely shape wax molds, onto which parylene is deposited as a support layer for the DSDT. Piezoelectric $\mathrm{ZnO}$ film is sputter-deposited on the parylene dome diaphragm. E-Solder silver epoxy is placed and cured on the back surface to function both as an acoustic backing and as structural support. Quarter wavelength thick parylene is deposited on the front side of the wafer for acoustic matching. The fabrication technique for the DSDTs is meant for low-cost mass production of the devices for high-frequency biomedical imaging. This method successfully prepared a $200 \mathrm{MHz}$ UHF transducer.

\section{Summary of This Section}

Through the broader understanding of ultrasonic transducers' focusing method, we can understand the difference between UHF devices' focusing and low-frequency devices' focusing. Table 5 presents these focusing methods' summary, which can compare the differences of these methods more intuitively.

\section{ACOUSTIC ENERGY TRANSMISSION MATCHING}

\section{Description of This Section}

When the ultrasonic wave is emitted from the ultrasonic transducer into the propagation medium, due to the large difference in acoustic impedance between the piezoelectric material and the propagation medium, most of the energy will be reflected, which leads to the low working efficiency of the ultrasonic device (Figure 10). In the low-frequency range, ceramics can be composited (Smith, 1986; Hou et al., 2018; Lin et al., 2018; Fei et al., 2019; Chen et al., 2020; Lin et al., 2020) to make the material acoustic impedance close to the propagation medium, improving energy transmission efficiency. The metamaterials mentioned in Material Selection of Ultrasound Generation section also have applications in acoustic impedance matching ( $\mathrm{Li}$ et al., 2017; Liu et al., 2018). These two methods both perform impedance matching by changing the spatial structure of the piezoelectric material. Although very effective, these operations are difficult to achieve in the UHF range. Therefore, we usually prefer to select the method by adding a matching layer to the piezoelectric material or lens surface for acoustic impedance matching in UHF. As the simplest and most effective matching method, quarterwavelength matching (Kossoff, 1966; Desilets et al., 1978; Rhee et al., 2001) has been active from the initial Mason model (Mason, 1948; Sittig, 1972) to the improved KLM model (Krimholtz et al., 1970; Leedom et al., 1971). Although easy to use, this method requires materials with specific acoustic impedance for matching. To obtain the matching layer with specified acoustic impedance, it is a general method by dope high acoustic impedance particles into low acoustic impedance materials. However, it is difficult to get a few microns or even sub-micron size for the doped particle. For this problem, the Mass-spring model (Toda and Thompson, 2010) and the Transmission line matching network (Ma et al., 2015) are introduced for the UHF ultrasonic devices' matching layer design. Furthermore, they also provide a good solution for the precise control of the matching layer's thickness. The research situation of these two methods will show in the follow-up.

\section{Novel Polymer-Metal Matching Layer}

In 2010, M. Toda and M. Thompson (Toda and Thompson, 2010) proposed a novel multi-layer polymer-metal structure for use in ultrasonic transducer impedance matching (Toda and Thompson, 2012; Brown et al., 2014) which is based on mass-spring model. In Figure 11 (Fei et al., 2015) we can see, after adding a metal-polymer structure matching layer to the ultrasonic transducer, its echo amplitude and bandwidth have been improved effectively. This method does not require materials with specific acoustic impedance and only needs to design metal and polymer layers of different thicknesses in combination with material characteristics to achieve the purpose of improving acoustic energy transmission. This laminated matching layer is conducive to the batch 


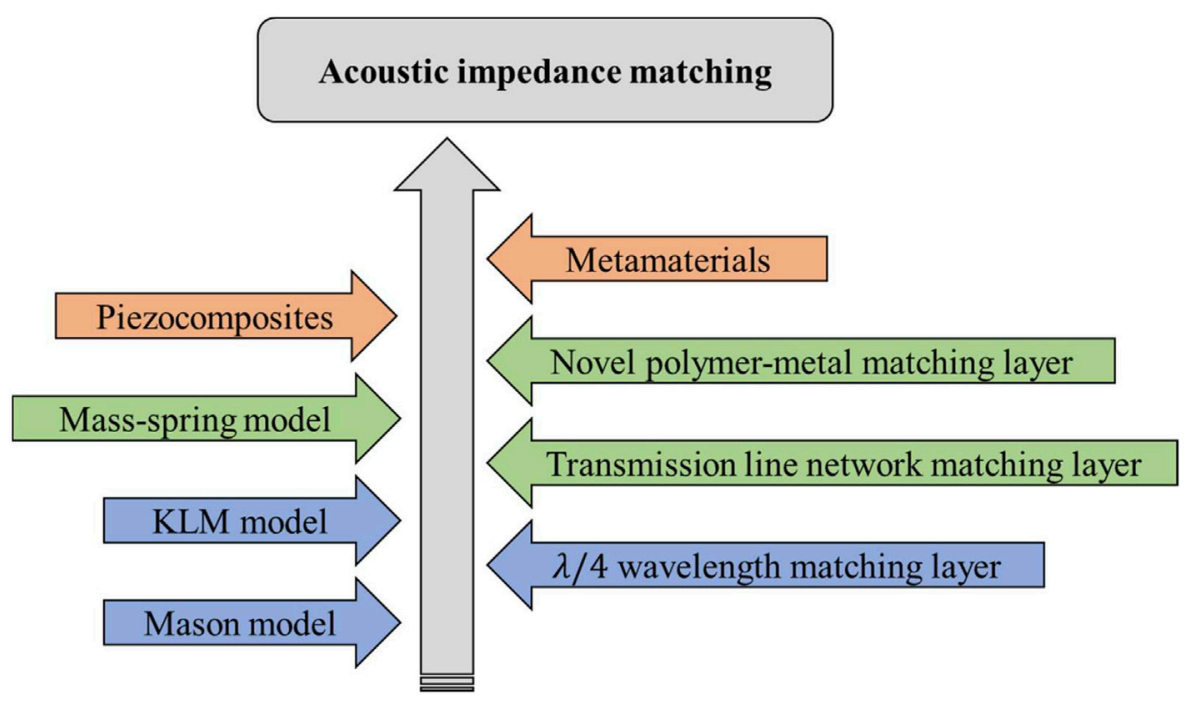

FIGURE 10 | Block diagram of Acoustic impedance matching (Rathod, 2020).
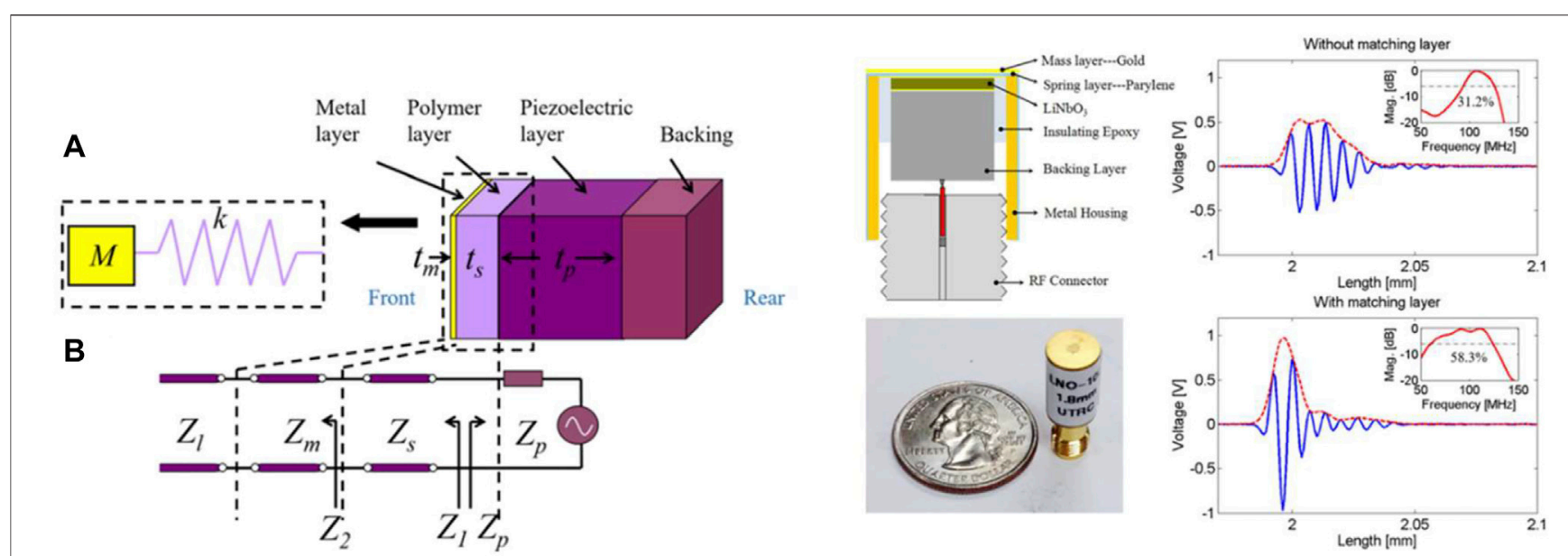

FIGURE 11 | Schematic diagram of the metal polymer matching layer based on mass-spring and its practical application in the transducer.

operation of the matching layer of the transducer and provides a feasible idea for the effective matching of ultra-high frequency ultrasonic devices.

\section{Transmission Line Network Matching Layer}

The transmission line matching network is implemented based on the KLM model. The acoustic impedance matching layer is designed by equating the acoustic parameters to the transmission line parameters and connecting them with the acoustic ports of the KLM model as shown in Figure 12 (Yang et al., 2020). It can be seen from the figure that after adding the matching layer, the echo does have a significant improvement. Therefore, the transmission line matching network is also an effective way to UHF transducer's energy transmission matching.

\section{Summary of This Section}

Piezoelectric composites and metamaterials are not suitable for improving the acoustic energy transmission matching of ultra-high frequency ultrasonic devices due to the difficulty of actual operation in the high-frequency range. The traditional quarter matching layer is not suitable for UHF ultrasonic devices due to the specific acoustic impedance. Mass-spring and transmission line matching networks can achieve highefficiency acoustic energy transmission by combining multilayer materials with different acoustic impedances. Theoretically speaking, the design and implementation process of the matching layer is compatible with the MEMS processing technology, with high repeatability and good development prospects. However, we should also consider the attenuation caused by the multi-layer matching layer 

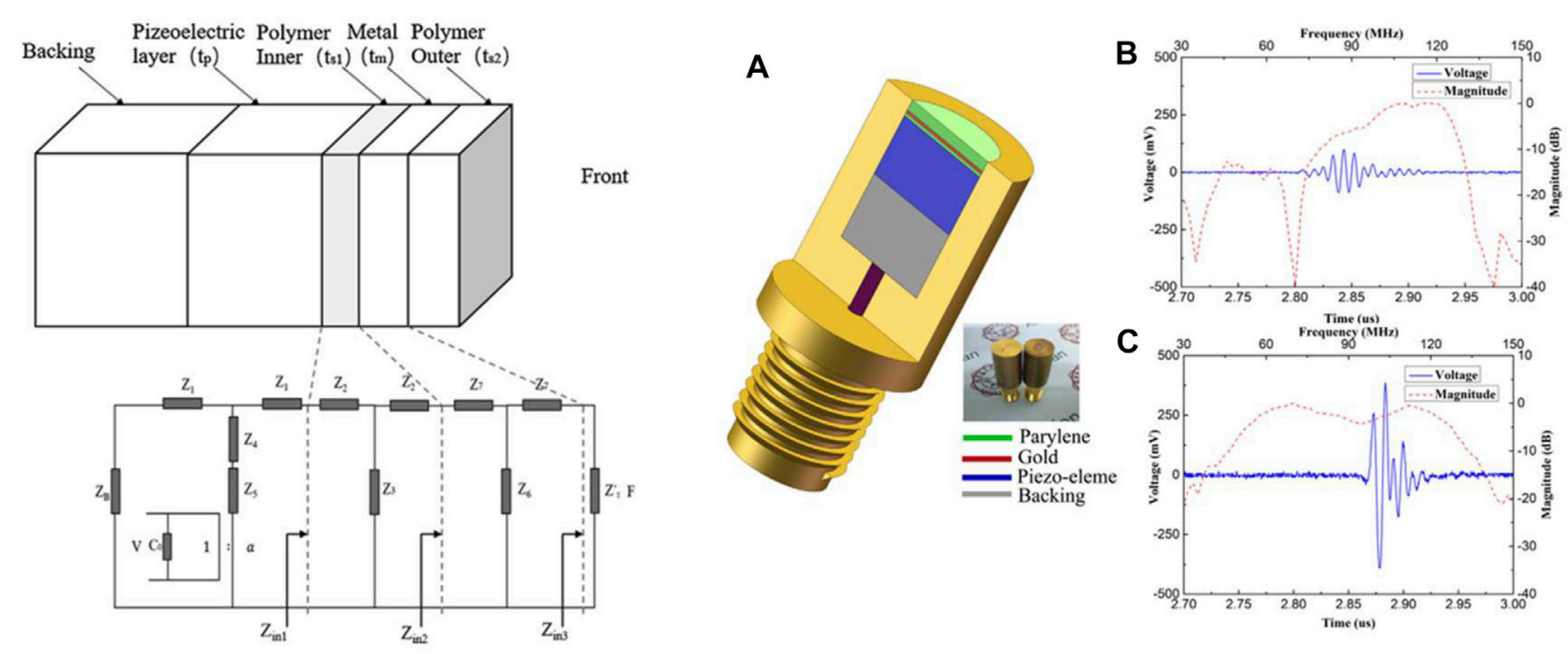

FIGURE 12 | Schematic diagram of the metal polymer matching layer based on transmission line matching network and its practical application in the transducer.

itself when designing the matching layer, so the acoustic impedance matching effect and the impact of material attenuation should consider comprehensively. Artificial intelligence ( $\mathrm{Li}$ et al., 2021a) has become popular in recent years is good at finding the optimal solution among multiple factors. In the design of multi-layer matching layers, there may be a lot of room for development.

\section{CONCLUSION}

This article starts with the introduction of the selection of materials for UHF ultrasonic transducers. First, it explains the reasons why the most commonly used ceramic materials cannot be used in the preparation of UHF devices and then mentions the more popular relaxation-based materials, but they also have disadvantages Therefore, it is not suitable for making UHF devices. The excellent material properties of LN single crystal make it occupy a place in UHF devices, from 100 to $500 \mathrm{MHz}$, but its difficult processing flow makes it difficult to break through the higher frequency limit. In addition, the processing flow is unstable, and the uniformity of the device caused by this makes it difficult to carry out mass production.

Things are always moving forward. The development of piezoelectric film materials has injected new impetus into the preparation of UHF transducers. Piezoelectric films prepared based on traditional ferroelectric materials solve the problem of difficult thickness control, and the piezoelectric films retain the excellent piezoelectric properties of bulk piezoelectric materials to a certain extent, and the UHF devices prepared by them have better performance. But this method can only be said to be a step to improve the thinning of piezoelectric materials in the traditional transducer manufacturing process. Due to the high temperature of densification and annealing during the preparation of piezoelectric film materials, the preparation of piezoelectric films and the production of transducers cannot be completely compatible. This leads to secondary processing of the prepared piezoelectric film, which is also quite difficult in actual operation. How to grow the piezoelectric film and the preparation of the transducer has good process compatibility is a very critical issue, and it is hoped that this problem can be solved through continuous process improvement in the future.

The development of the semiconductor industry has made MEMS technology increasingly mature, and piezoelectric films made of $\mathrm{ZnO}$ and AlN, which are commonly used semiconductor materials, have also joined the family of ultra-high frequency ultrasonic transducers. The mature MEMS technology makes the piezoelectric film and the transducer preparation compatible and does not require secondary processing. The preparation of the piezoelectric film is a step included in the MEMS transducer preparation process. This gives a better guarantee for the consistency of UHF devices and provides a basis for mass production. But all things have advantages and disadvantages. The disadvantage of using semiconductor materials to replace traditional ferroelectric materials is that the piezoelectric performance is relatively poor. Piezoelectric materials determine the final performance of the device, so the problem here is how to improve the piezoelectric performance of the material. There have been a few reports on this aspect of research, such as the above-mentioned modification of Sc doping and $\mathrm{Yb}$ doping to improve the piezoelectricity of AlN. This is a key issue that requires more researchers to join.

In addition to material selection, the focus design of UHF ultrasound devices is another key point. At present, the most 
commonly used focusing methods in UHF ultrasound devices are acoustic lens focusing and self-focusing. There are also a certain number of reports on UHF ultrasound devices in this regard. This article also mentioned more focusing methods currently used in low-frequency bands, such as spherical pressure focusing, mechanical focusing, and acoustic lens focusing. There are also some interesting focusing methods, such as ultrasonic super-surface, liquid lens focusing. By understanding these various focusing methods, we can diverge our thinking. When we encounter problems in the focus design of UHF ultrasound devices, it may provide us with clever solutions.

The last key point mentioned in this article is the problem of acoustic energy transmission. As we all know, the propagation of sound requires a medium. In the application of UHF ultrasonic transducers, the medium we mentioned is usually water, and the acoustic impedance of water is only $1.5 \mathrm{MRlays}$, but piezoelectric materials are often much larger than this. If no matching layer is added, the acoustic energy is directly emitted from the piezoelectric material into the water, and most of the energy will be reflected due to the large acoustic impedance difference. This will cause the device to work very inefficiently. The traditional quarter acoustic impedance matching layer has explained why it is not suitable for UHF ultrasonic devices. A new design method of metal-polymer structure matching layer is mentioned, and its applicability in ultrahigh frequency ultrasonic devices is explained.

\section{AUTHOR CONTRIBUTIONS}

JC was responsible for collecting, sorting out relevant information and writing the paper. Other authors provided advice and help. All authors contributed to the article and approved the submitted version.

\section{FUNDING}

This work was supported by the National Natural Science Foundation of China (No: 61974110), the Key Projects of National Defense Basic Research Program of National Defense Science and Industry Administration (JCKY2019210B003), the Natural Science Foundation of Shaanxi Province (No: 2020JM-205, 2021JM-253), and the Fundamental Research Funds for the University of People's Armed Police (No: WJY201923, WJY202147).

\section{REFERENCES}

Al Jahdali, R., and Wu, Y. (2016). High Transmission Acoustic Focusing by Impedance-Matched Acoustic Meta-Surfaces. Appl. Phys. Lett. 108 (3), 031902. doi:10.1063/1.4939932

Barrow, D. A., Petroff, T. E., Tandon, R. P., and Sayer, M. (1997). Characterization of Thick lead Zirconate Titanate Films Fabricated Using a New Sol Gel Based Process. Journal Applied Physics 81, 876-881. doi:10.1063/1.364172

\section{SUPPLEMENTARY MATERIAL}

The Supplementary Material for this article can be found online at: https://www.frontiersin.org/articles/10.3389/fmats.2021.733358/ full\#supplementary-material

Supplementary figure S1 I Schematic diagram of acoustic tweezers (left) and ultrasound scanning microscope (right).

Supplementary figure $\mathbf{S 2}$ | Ceramic grains under the microscope.

Supplementary figure S3 | A photograph of LN transducer and cross section of piezoelectric layer (left); High resolution ultrasound image of zebrafish eye (right).

Supplementary figure S4 | Cross section of 20 um PZT film.

Supplementary figure S5 | Pulse echo and FFT of $100 \mathrm{MHz} P Z T$ thick film transducer (top); Experimental pulse echo and FFT of $150 \mathrm{MHz}$ PZT thick film transducer (bottom left); Simulated pulse echo and FFT of $150 \mathrm{MHz}$ PZT thick film transducer (bottom right).

Supplementary figure S6 I A photograph of $300 \mathrm{MHz}$ transducer (top left); Schematic diagram of 0-3 composite PZT film (top right); time-domain pulse/ echo response (solid line) and frequency spectrum (dashed line) of 100-300 MHz transducer (bottom).

Supplementary figure S7 | A photograph of $193 \mathrm{MHz}$ KNN-LSO needle planar transducer (top left); schematic diagram of $225 \mathrm{MHz}$ KNN/BNT piston focusing transducer (bottom left); time-domain pulse/echo response and frequency spectrum of $193 \mathrm{MHz}$ KNN-LSO needle planar transducer (top right); time-domain pulse/echo response and frequency spectrum of $225 \mathrm{MHz}$ KNN/BNT piston focus transducer (lower right).

Supplementary figure S8 | Time-domain pulse/echo response (solid line) and frequency spectrum (dashed line) of 170-320 MHz KNN/BNT transducer.

Supplementary figure S9 | Frequency curve of the dielectric coefficient of XPMNPT-(1-x)PZT composite film under different PZT doping ratios (left); time-domain pulse/echo response (solid line) and frequency spectrum (dashed line) of 0.9PMNPT-0.1PZT composite film transducer (right).

Supplementary figure $\mathbf{S 1 0 ~ | ~ F e r r o e l e c t r i c ~ h y s t e r e s i s ~ l o o p s ~ o f ~ P M N - P T - P Z T ~}$ composite film under different Ag doping concentration (top left); curve of influence of Ag concentration on the dielectric constant of PMN-PT-PZT composite film at $1 \mathrm{KHz}$ (top right); a photograph of silver-doped PMN-PT-PZT needle transducer (bottom left); time-domain pulse/echo response (solid line) and frequency spectrum (dashed line) of silver-doped PMN-PT-PZT needle transducer (bottom right).

Supplementary figure S11 | Preparation process of spherical pressure focusing transducer.

Supplementary figure S12 | A photograph of needle type mechanical focused ultrasound transducer (top left); piezoelectric materials after mechanical dimpling under optical microscope (top right); IVUS mechanical focus transducer preparation process (bottom).

Supplementary figure $\mathbf{S 1 3}$ | Two types of acoustic metasurface lenses and simulation diagram of the focusing effect of two acoustic metasurface lenses.

Supplementary figure S14 | Schematic and physical image of liquid lens.

Supplementary figure S15| The flow chart of prepare Dome-Shaped-Diaphragm Transducers (left) and photographs of Dome-Shaped-Diaphragm Transducer (right).

Brown, J., Sharma, S., Leadbetter, J., Cochran, S., and Adamson, R. (2014). Massspring Matching Layers for High-Frequency Ultrasound Transducers: a New Technique Using Vacuum Deposition. IEEE Trans. Ultrason. Ferroelect., Freq. Contr. 61 (11), 1911-1921. doi:10.1109/TUFFC.2014.006480

Cannata, J. M., Ritter, T. A., Wo-Hsing Chen, W.-H., and Shung, K. K. (20002000). Design of Focused Single Element (50-100 MHz) Transducers Using Lithium Niobate. IEEE Ultrason. Symp. 2, 1129-1133. doi:10.1109/ULTSYM.2000.921524

Cannata, J. M., Ritter, T. A., Wo-Hsing Chen, W., Silverman, R. H., and Shung, K. K. (2003). Design of Efficient, Broadband Single-Element $(20-80 \mathrm{MHz})$ Ultrasonic 
Transducers for Medical Imaging Applications. IEEE Trans. Ultrason. Ferroelect., Freq. Contr. 50, 1548-1557. doi:10.1109/TUFFC.2003.1251138

Cannata, J. M., Williams, J. A., Zhou, Q. F., Sun, L., Shung, K. K., Yu, H., et al. (2008). Self-focused $\mathrm{ZnO}$ Transducers for Ultrasonic Biomicroscopy. Journal Applied Physics 103, 084109. doi:10.1063/1.2907716

Chen, D., Hou, C., Fei, C., Li, D., Lin, P., Chen, J., et al. (2020). An Optimization Design Strategy of 1-3 Piezocomposite Ultrasonic Transducer for Imaging Applications. Mater. Today Commun. 24, 100991. doi:10.1016/j.mtcomm.2020.100991

Chen, H., Xia, H., Wang, J., Zhang, J., Xu, J., and Fan, S. (2003). Growth of LiNbO3 Crystals by the Bridgman Method. Journal Crystal Growth 256, 219-222. doi:10.1016/S0022-0248(03)01361-7

Chen, X., Fei, C., Chen, Z., Chen, R., Yu, P., Chen, Z., et al. (2016). Simulation and Fabrication of 0-3 Composite PZT Films for Ultrahigh Frequency (100-300 $\mathrm{MHz}$ ) Ultrasonic Transducers. Journal Applied Physics 119, 094103. doi:10.1063/1.4942857

Chen, X., Lam, K. H., Chen, R., Chen, Z., Yu, P., Chen, Z., et al. (2017). An Adjustable Multi-Scale Single Beam Acoustic Tweezers Based on Ultrahigh Frequency Ultrasonic Transducer. Biotechnol. Bioeng. 114, 2637-2647. doi:10.1002/bit.26365

Chen, Y., Lam, K.-H., Zhou, D., Yue, Q., Yu, Y., Wu, J., et al. (2014). High Performance Relaxor-Based Ferroelectric Single Crystals for Ultrasonic Transducer Applications. Sensors 14, 13730-13758. doi:10.3390/s140813730

Chen, Y., Lam, K. H., Zhou, D., Cheng, W. F., Dai, J. Y., Luo, H. S., et al. (2013). High Frequency PMN-PT Single crystal Focusing Transducer Fabricated by a Mechanical Dimpling Technique. Ultrasonics 53 (2), 345-349. doi:10.1016/ j.ultras.2012.06.017

Desilets, C. S., Fraser, J. D., and Kino, G. S. (1978). The Design of Efficient BroadBand Piezoelectric Transducers. IEEE Trans. Son. Ultrason. 25, 115-125. doi:10.1109/T-SU.1978.31001

Fei, C., Chiu, C. T., Chen, X., Chen, Z., Ma, J., Zhu, B., et al. (2016). Ultrahigh Frequency (100 MHz-300 MHz) Ultrasonic Transducers for Optical Resolution Medical Imagining. Sci. Rep. 6, 28360. doi:10.1038/srep28360

Fei, C., Hsu, H.-S., Vafanejad, A., Li, Y., Lin, P., Li, D., et al. (2017). Ultrahigh Frequency $\mathrm{ZnO}$ Silicon Lens Ultrasonic Transducer for Cell-Size Microparticle Manipulation. Journal Alloys Compounds 729, 556-562. doi:10.1016/j.jallcom.2017.09.113

Fei, C., Lin, P., Li, D., Wu, Y., Wu, R., Chen, J., et al. (2019). Fabrication and Characterization of High-Sensitivity Ultrasonic Transducers with Functionally Graded Design. IEEE Sensors J. 19 (16), 6650-6654. doi:10.1109/ jsen.2019.2905625

Fei, C., Ma, J., Chiu, C. T., Williams, J. A., Fong, W., Chen, Z., et al. (2015). Design of Matching Layers for High-Frequency Ultrasonic Transducers. Appl. Phys. Lett. 107 (12), 123505. doi:10.1063/1.4931703

Fei, C., Yang, Y., Guo, F., Lin, P., Chen, Q., Zhou, Q., et al. (2018a). PMN-PT Single Crystal Ultrasonic Transducer with Half-Concave Geometric Design for IVUS Imaging. IEEE Trans. Biomed. Eng. 65 (9), 2087-2092. doi:10.1109/ TBME.2017.2784437

Fei, C., Zhao, T., Wang, D., Quan, Y., Lin, P., Li, D., et al. (2018b). High Frequency Needle Ultrasonic Transducers Based on Lead-Free Co Doped Na0.5Bi4.5Ti4O15 Piezo-Ceramics. Micromachines 9 (6), 291. doi:10.3390/ mi9060291

Feng, G.-H., Sharp, C. C., Zhou, Q. F., Pang, W., Kim, E. S., and Shung, K. K. (2005). Fabrication of MEMS ZnO Dome-Shaped-Diaphragm Transducers for High-Frequency Ultrasonic Imaging. J. Micromech. Microeng. 15, 586-590. doi:10.1088/0960-1317/15/3/021

Foster, F. S., Ryan, L. K., and Turnbull, D. H. (1991). Characterization of lead Zirconate Titanate Ceramics for Use in Miniature High-Frequency (20-80 $\mathrm{MHz}$ ) Transducers. IEEE Trans. Ultrason. Ferroelect., Freq. Contr. 38, 446-453. doi:10.1109/58.84289

Haertling, G. H. (1999). Ferroelectric Ceramics: History and Technology. Journal American Ceramic Society 82, 797-818. doi:10.1111/j.1151-2916.1999.tb01840.x

Hashimoto, H., Tanaka, S., and Sato, K. (1991). "Silicon Acoustic Lens for Scanning Acoustic Microscope (SAM)," in TRANSDUCERS '91: 1991 International Conference on Solid-State Sensors and Actuators. Digest of Technical Papers, San Francisco, CA, USA, 24-27 June 1991 (IEEE), 853-859. doi:10.1109/SENSOR.1991.149019

Hirata, K., Mori, Y., Yamada, H., Uehara, M., Anggraini, S. A., and Akiyama, M. (2021). Significant Enhancement of Piezoelectric Response in AlN by $\mathrm{Yb}$ Addition. Materials 14, 309. doi:10.3390/ma14020309
Hou, S., Yang, X., Fei, C., Sun, X., Chen, Q., Lin, P., et al. (2018). Fabrication of PMN-PT/Epoxy 2-2 Composite Ultrasonic Transducers and Analysis Based on Equivalent Circuit Model. J. Elec. Materi. 47 (11), 6842-6847. doi:10.1007/ s11664-018-6603-0

Hsu, H.-S., Benjauthrit, V., Wei, Q., Huang, Y., Zhou, Q., and Shung, K. K. (2013). Silver Doped 0.9PMN-PT-0.1PZT Composite Films for Very High Frequency Ultrasonic Transducer Applications. Appl. Phys. A. 111, 459-463. doi:10.1007/ s00339-013-7558-x

Hsu, H.-S., Benjauthrit, V., Zheng, F., Chen, R., Huang, Y., Zhou, Q., et al. (2012). PMNPT-PZT Composite Films for High Frequency Ultrasonic Transducer Applications. Sensors Actuators A: Phys. 179, 121-124. doi:10.1016/j.sna.2012.02.031

Jakob, A., Bender, M., Knoll, T., Lemor, R., Lehnert, T., Koch, M., et al. (2009). "Comparison of Different Piezoelectric Materials for GHz Acoustic Microscopy Transducers," in 2009 IEEE International Ultrasonics Symposium, Rome, Italy, 20-23 Sept. 2009 (IEEE), 1722-1725. doi:10.1109/ULTSYM.2009.5442024

Jakob, A., Weiss, E. C., Knoll, T., Bauerfeld, F., Hermann, J., and Lemor, R. (2007). "P2E-5 Silicon Based GHz Acoustic Lenses for Time Resolved Acoustic Microscopy," in 2007 IEEE Ultrasonics Symposium, New York, NY, USA, 28-31 Oct. 2007 (IEEE), 1605-1608. doi:10.1109/ULTSYM.2007.404

Kamel, T. M., and de With, G. (2008). Grain Size Effect on the Poling of Soft $\mathrm{Pb}(\mathrm{Zr}, \mathrm{Ti}) \mathrm{O} 3$ Ferroelectric Ceramics. Journal European Ceramic Society 28, 851-861. doi:10.1016/j.jeurceramsoc.2007.08.010

Kong, L. B., Zhu, W., and Tan, O. K. (2000). Preparation and Characterization of $\mathrm{Pb}(\mathrm{Zr} 0.52 \mathrm{Ti} 0.48) \mathrm{O} 3$ Ceramics from High-Energy ball Milling Powders. Materials Letters 42, 232-239. doi:10.1016/S0167-577X(99)00190-1

Kossoff, G. (1966). The Effects of Backing and Matching on the Performance of Piezoelectric Ceramic Transducers. IEEE Trans. Son. Ultrason. 13 (1), 20-30. doi:10.1109/T-SU.1966.29370

Krimholtz, R., Leedom, D. A., and Matthaei, G. L. (1970). New Equivalent Circuits for Elementary Piezoelectric Transducers. Electron. Lett. 6 (13), 398-399. doi:10.1049/el: 19700280

Kushida, K., Takeuchi, H., Kanda, H., and Yamaguchi, S. (1989). 100 MHz Band Ultrasonic Transducers Utilizing Epitaxially Grown ZnO Films. Jpn. J. Appl. Phys. 28, 260. doi:10.7567/JJAPS.28S1.260

Lam, K. H., Chen, Y., Cheung, K. F., and Dai, J. Y. (2012). PMN-PT Single crystal Focusing Transducer Fabricated Using a Mechanical Dimpling Technique. Ultrasonics 52 (1), 20-24. doi:10.1016/j.ultras.2011.06.004

Lam, K. H., Hsu, H.-S., Li, Y., Lee, C., Lin, A., Zhou, Q., et al. (2013a). Ultrahigh Frequency Lensless Ultrasonic Transducers for Acoustic Tweezers Application. Biotechnol. Bioeng. 110, 881-886. doi:10.1002/bit.24735

Lam, K. H., Ji, H. F., Zheng, F., Ren, W., Zhou, Q., and Shung, K. K. (2013b). Development of lead-free Single-Element Ultrahigh Frequency $(170-320 \mathrm{MHz})$ Ultrasonic Transducers. Ultrasonics 53 (5), 1033-1038. doi:10.1016/ j.ultras.2013.01.012

Lau, S.-t., Li, X., Zhang, X., Zhou, Q., Shung, K. K., Ji, H., et al. (2010a). "High Frequency Ultrasonic Transducer with KNN/BNT 0-3 Composite Active Element," in 2010 IEEE International Ultrasonics Symposium, San Diego, CA, USA, 11-14 Oct. 2010 (IEEE), 76-79. doi:10.1109/ULTSYM.2010.5935849

Lau, S. T., Ji, H. F., Li, X., Ren, W., Zhou, Q., and Shung, K. K. (2011). KNN/BNT Composite Lead-Free Films for High-Frequency Ultrasonic Transducer Applications. IEEE Trans. Ultrason. Ferroelect., Freq. Contr. 58, 249-254. doi:10.1109/TUFFC.2011.1793

Lau, S. T., Li, X., Zhou, Q. F., Shung, K. K., Ryu, J., and Park, D.-S. (2010b). Aerosoldeposited KNN-LSO lead-free Piezoelectric Thick Film for High Frequency Transducer Applications. Sensors Actuators A: Phys. 163, 226-230. doi:10.1016/ j.sna.2010.08.020

Leedom, D. A., Krimholtz, R., and Matthaei, G. L. (1971). Equivalent Circuits for Transducers Having Arbitrary Even- or Odd-Symmetry Piezoelectric Excitation. IEEE Trans. Son. Ultrason. 18 (3), 128-141. doi:10.1109/T-SU.1971.29608

Li, D., Fei, C., Zhang, Q., Li, Y., Yang, Y., and Zhou, Q. (2018). Ultrahigh Frequency Ultrasonic Transducers Design with Low Noise Amplifier Integrated Circuit. Micromachines 9 (10), 515. doi:10.3390/mi9100515

Li, Z., Chen, D., Fei, C., Li, D., Feng, W., and Yang, Y. (2021a). Optimization Design of Ultrasonic Transducer with Multimatching Layer. IEEE Trans. Ultrason. Ferroelect., Freq. Contr. 68 (6), 2202-2211. doi:10.1109/TUFFC.2021.3059671

Li, Z., Guo, R., Chen, D., Fei, C., Yang, X., Li, D., et al. (2021b). An Efficient Optimization Design of Liquid Lens for Acoustic Pattern Control. IEEE Trans. Ultrason. Ferroelect., Freq. Contr. 68 (5), 1546-1554. doi:10.1109/TUFFC.2020.3040174 
Li, Z., Guo, R., Fei, C., Li, D., Chen, D., Zheng, C., et al. (2021c). Liquid Lens with Adjustable Focus for Ultrasonic Imaging. Appl. Acoust. 175, 107787. doi:10.1016/j.apacoust.2020.107787

Li, Z., Yang, D.-Q., Liu, S.-L., Yu, S.-Y., Lu, M.-H., Zhu, J., et al. (2017). Broadband Gradient Impedance Matching Using an Acoustic Metamaterial for Ultrasonic Transducers. Sci. Rep. 7 (1), 42863. doi:10.1038/srep42863

Lim, H. G., and Shung, K. K. (2017). Quantification of Inter-erythrocyte Forces with Ultra-high Frequency (410 MHz) Single Beam Acoustic Tweezer. Ann. Biomed. Eng. 45, 2174-2183. doi:10.1007/s10439-017-1863-Z

Lin, P., Fei, C., Hou, S., Zhao, T., Chen, Q., Quan, Y., et al. (2018). 0.36BiScO30.64PbTiO3/Epoxy 1-3 Composite for Ultrasonic Transducer Applications. IEEE Sensors J. 18 (14), 5685-5690. doi:10.1109/jsen.2018.2837868

Lin, P., Zhang, L., Fei, C., Li, D., Wu, R., Chen, Q., et al. (2020). Novel Multi-LayerComposites Design for Ultrasonic Transducer Applications. Compos. Structures 245, 112364. doi:10.1016/j.compstruct.2020.112364

Liu, C., Luo, J., and Lai, Y. (2018). Acoustic Metamaterials with Broadband and Wide-Angle Impedance Matching. Phys. Rev. Mater. 2 (4), 045201. doi:10.1103/ PhysRevMaterials.2.045201

Luo, J. T., Fan, B., Zeng, F., and Pan, F. (2009). Influence of Cr-Doping on Microstructure and Piezoelectric Response of AlN Films. J. Phys. D: Appl. Phys. 42, 235406. doi:10.1088/0022-3727/42/23/235406

Ma, J., Steer, M. B., and Jiang, X. (2015). An Acoustic Filter Based on Layered Structure. Appl. Phys. Lett. 106 (11), 111903. doi:10.1063/1.4915100

Makra, A., Bost, W., Kallo, I., Horvath, A., Fournelle, M., and Gyongy, M. (2020). Enhancement of Acoustic Microscopy Lateral Resolution: A Comparison between Deep Learning and Two Deconvolution Methods. IEEE Trans. Ultrason. Ferroelect., Freq. Contr. 67 (1), 136-145. doi:10.1109/ TUFFC.2019.2940003

Marechal, P., Levassort, F., Holc, J., Tran-Huu-Hue, L.-P., Kosec, M., and Lethiecq, M. (2006). High-frequency Transducers Based on Integrated Piezoelectric Thick Films for Medical Imaging. IEEE Trans. Ultrason. Ferroelect., Freq. Contr. 53, 1524-1533. doi:10.1109/TUFFC.2006.1665110

Mason, W. P. (1948). Electromechanical Transducers and Wave Filters. D. Van Nostrand Company.

Molarius, J., Kaitila, J., Pensala, T., and Ylilammi, M. (2003). Piezoelectric ZnO Films by r.F. Sputtering. Journal Materials Science-Materials Electronics 14, 431-435. doi:10.1023/A:1023929524641

Park, S.-E., and Shrout, T. R. (1997b). Ultrahigh Strain and Piezoelectric Behavior in Relaxor Based Ferroelectric Single Crystals. Journal Applied Physics 82, 1804-1811. doi:10.1063/1.365983

Pérez, J. A., Soares, M. R., Mantas, P. Q., and Senos, A. M. R. (2005). Microstructural Design of PZT Ceramics. J. Eur. Ceram. Soc. 25, 2207-2210. doi:10.1016/j.jeurceramsoc.2005.03.031

Randall, C., Kim, N., Kucera, J., Cao, W., and Shrout, T. (1998). Intrinsic and Extrinsic Size Effects in fine-grained Morphotropic-Phase-Boundary lead Zirconate Titanate Ceramics. Journal American Ceramic Society 81, 677-688.

Rathod, V. T. (2020). A Review of Acoustic Impedance Matching Techniques for Piezoelectric Sensors and Transducers. Sensors (Basel) 20 (14), 4051. doi:10.3390/s20144051

Rhee, S., Ritter, T. A., Shung, K. K., Wang, H., and Cao, W. (2001). "Materials for Acoustic Matching in Ultrasound Transducers," in 2001 IEEE Ultrasonics Symposium. Proceedings. An International Symposium (Cat. No.01CH37263), Atlanta, GA, USA, 7-10 Oct. 2001 (IEEE), 1051-1055. doi:10.1109/ULTSYM.2001.991900

Sangsubun, C., Watcharapasorn, A., and Jiansirisomboon, S. (2008). Densification and Microstructure of lead Zirconate Titanate Ceramics Fabricated from a Triol Sol-Gel Powder. Current Applied Physics 8, 61-65. doi:10.1016/j.cap.2007.04.009

Sano, K., Karasawa, R., and Yanagitani, T. (2018). ScAlN Thick-Film Ultrasonic Transducer in 40-80 MHz. IEEE Transactions Ultrasonics Ferroelectrics Frequency Control 65, 2097-2102. doi:10.1109/TUFFC.2018.2865791

Seung-Eek Park, S., and Shrout, T. R. (1997a). Characteristics of Relaxor-Based Piezoelectric Single Crystals for Ultrasonic Transducers. IEEE Trans. Ultrason. Ferroelect., Freq. Contr. 44, 1140-1147. doi:10.1109/58.655639

Sittig, E. K. (1972). "5 - Design and Technology of Piezoelectric Transducers for Frequencies above $100 \mathrm{MHz}$," in Physical Acoustics. Editors W. P. Mason and R. N. Thurston (Academic Press), 221-275. doi:10.1016/b978-0-12-3956705.50010-6
Smith, W. A. (1986). "Composite Piezoelectric Materials for Medical Ultrasonic Imaging Transducers - A Review," in Sixth IEEE International Symposium on Applications of Ferroelectrics, Bethlehem, PA, USA, 8-11 June 1986 (IEEE), 249-256. doi:10.1109/ISAF.1986.201136

Toda, M., and Thompson, M. (2012). Detailed Investigations of Polymer/metal Multilayer Matching Layer and Backing Absorber Structures for Wideband Ultrasonic Transducers. IEEE Trans. Ultrason. Ferroelectrics, Frequency Control. 59 (2), 231-242. doi:10.1109/TUFFC.2012.2183

Toda, M., and Thompson, M. (2010). Novel Multi-Layer Polymer-Metal Structures for Use in Ultrasonic Transducer Impedance Matching and Backing Absorber Applications. IEEE Trans. Ultrason. Ferroelectrics, Frequency Control. 57 (12), 2818-2827. doi:10.1109/TUFFC.2010.1755

Uecker, R. (2014). The Historical Development of the Czochralski Method. Journal Crystal Growth 401, 7-24. doi:10.1016/j.jcrysgro.2013.11.095

Vispute, R., Talyansky, V., Trajanovic, Z., Choopun, S., Downes, M., Sharma, R., et al. (1997). High Quality Crystalline ZnO Buffer Layers on Sapphire (001) by Pulsed Laser Deposition for III-V Nitrides. Applied Physics Letters 70, 2735-2737. doi:10.1063/1.119006

Weiss, E. C., Anastasiadis, P., Pilarczyk, G., Lemor, R. M., and Zinin, P. V. (2007). Mechanical Properties of Single Cells by High-Frequency Time-Resolved Acoustic Microscopy. IEEE Transactions Ultrasonics Ferroelectrics Frequency Control 54 (11), 2257-2271. doi:10.1109/tuffc.2007.530

Wistrela, E., Schmied, I., Schneider, M., Gillinger, M., Mayrhofer, P., Bittner, A., et al. (2018). Impact of Sputter Deposition Parameters on the Microstructural and Piezoelectric Properties of CrxAll (-) N-X Thin Films. Thin Solid Films 648, 76-82. doi:10.1016/j.tsf.2018.01.003

Yang, X., Fei, C., Li, D., Sun, X., Hou, S., Chen, J., et al. (2020). Multi-layer PolymerMetal Structures for Acoustic Impedance Matching in High-Frequency Broadband Ultrasonic Transducers Design. Appl. Acoust. 160, 107123. doi:10.1016/j.apacoust.2019.107123

Zhang, T., Chen, R., Zhang, Z., Li, R., Tang, X., Wang, X., et al. (2017). "High Frequency Single crystal Ultrasonic Transducers up to $100 \mathrm{MHz}$ for High Resolution Ophthalmic Imaging Applications," in 2017 IEEE International Ultrasonics Symposium, Washington, DC, USA, 6-9 Sept. 2017 (IEEE), 1. doi:10.1109/ULTSYM.2017.8092279

Zhou, Q. F., Sharp, C., Cannata, J. M., Shung, K. K., Feng, G. H., and Kim, E. S. (2007). Self-focused High Frequency Ultrasonic Transducers Based on ZnO Piezoelectric Films. Appl. Phys. Lett. 90 (11). doi:10.1063/1.2712813

Zhu, B., Fei, C., Wang, C., Zhu, Y., Yang, X., Zheng, H., et al. (2017). Self-Focused AIScN Film Ultrasound Transducer for Individual Cell Manipulation. ACS Sensors 2, 172-177. doi:10.1021/acssensors.6b00713

Zhu, B., Wu, D., Zhou, Q., Shi, J., and Shung, K. (2008). Lead Zirconate Titanate Thick Film with Enhanced Electrical Properties for High Frequency Transducer Applications. Applied Physics Letters 93, 012905. doi:10.1063/1.2956408

Zhu, Y.-F., Fan, X.-D., Liang, B., Yang, J., Yang, J., Yin, L.-l., et al. (2016). Multifrequency Acoustic Metasurface for Extraordinary Reflection and Sound Focusing. AIP Adv. 6 (12), 121702. doi:10.1063/1.4968607

Conflict of Interest: The authors declare that the research was conducted in the absence of any commercial or financial relationships that could be construed as a potential conflict of interest.

Publisher's Note: All claims expressed in this article are solely those of the authors and do not necessarily represent those of their affiliated organizations, or those of the publisher, the editors and the reviewers. Any product that may be evaluated in this article, or claim that may be made by its manufacturer, is not guaranteed or endorsed by the publisher.

Copyright () 2022 Chen, Fei, Lin, Gao, Zhang, Quan, Chen, Li and Yang. This is an open-access article distributed under the terms of the Creative Commons Attribution License (CC BY). The use, distribution or reproduction in other forums is permitted, provided the original author(s) and the copyright owner(s) are credited and that the original publication in this journal is cited, in accordance with accepted academic practice. No use, distribution or reproduction is permitted which does not comply with these terms. 